
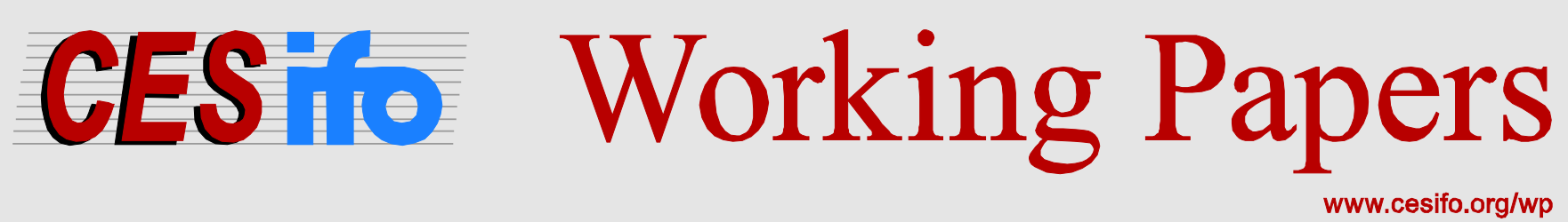

\title{
Employment Protection and the Market for Innovations
}

\author{
Andreas Bastgen \\ Christian Holzner
}

CESIFO WORKING PAPER NO. 5275

CATEGORY 3: SOCIAL PROTECTION

MARCH 2015

An electronic version of the paper may be downloaded

- from the SSRN website:

- from the RePEc website:

- from the CESifo website:

WwW.SSRN.com

www.RePEc.org

www.CESifo-group.org/wp 


\title{
Employment Protection and the Market for Innovations
}

\begin{abstract}
We study the effects of employment protection taking into account that firms can invest in R\&D or buy new technologies in order to restore their productivity. To do so we develop an equilibrium matching model with an imperfect labor and innovation market. If employment protection is introduced, firms' willingness to pay for product or process innovations increases. This shifts economic activity towards firms specializing in process and product innovation and triggers entry of new start-ups. We calibrate our model to match aggregate US labor and product market statistics and show that our model generates the estimated negative impact of wrongful dismissal laws in the US on productivity and the positive effect on the number of innovations and firms.
\end{abstract}

JEL-Code: J640, J650, O310, O380.

Keywords: employment protection, firing costs, innovations, patents, productivity, market imperfections.

\author{
Andreas Bastgen \\ University of Munich \\ Department of Economics \\ Ludwigstr. 28 (Vgb.) \\ Germany - 80539 Munich \\ andreas.bastgen@econ.Imu.de
}

\author{
Christian Holzner \\ Ifo Institute - Leibniz Institute for \\ Economic Research \\ at the University of Munich \\ Poschingerstrasse 5 \\ Germany-81679 Munich \\ holzner@ifo.de
}

March 13, 2015

The authors thank Moritz Kuhn, Gerard Pfann and workshop/seminar participants in Mainz, Masstricht and Cologne for their comments. 


\section{Introduction}

Employment protection is thought to ensure workers against temporary productivity shocks. While most negative productivity shocks to a firm are exogenous, like a drop in demand due to changes in taste or an increase in competition due to new production technologies of competitors, positive productivity shocks are usually the result of process or product innovation and are hence endogenous. Product or process innovation can either be done within a firm through own R\&D investment or it can be bought in the market (e.g. new machinery or patent licensing). If we study the effects of employment protection we should therefore take into account that firms are able to restore their productivity.

The literature on employment protection so far has not considered the interaction between employment protection and firms' ability to restore their productivity. One strand of the literature on employment protection documented a negative effect of employment protection on productivity through inefficient worker reallocation. ${ }^{1}$ Another strand of the literature has shown theoretcially or found empirically that employment protection can increase productivity by increasing job duration, which provides an incentive for workers and firms to invest in firm-specific capital. ${ }^{2}$ While the latter literature has shown that employment protection can have a positive effect on innovation investment, it still treats positive productivity shocks as exogenous.

We develop an equilibrium matching model with an imperfect labor and innovation market. We assume labor market frictions, because without labor market frictions laid off workers could be reemployed immediately by other firms, which makes employment protection redundant. We assume frictions in the innovation market, because without frictions firms could immediately purchase the machinery (process innovation) or product idea (product innovation) necessary to restore productivity. We model both markets as

\footnotetext{
${ }^{1}$ Negative productivity effects from inefficient labor reallocation are found by Hopenhayn and Rogerson (1993), Griliches and Regev (1995), Olley and Pakes (1996), Foster, Haltiwanger, and Krizan (2001), Disney, Haskel, and Heden (2003), Baldwin and Gu (2006) and Bartelsman, Haltiwanger, and Scarpetta (2009) among others.

${ }^{2}$ Akerlof (1984), Soskice (1997), Zoega and Booth (2003), Belot, Boone, and Ours (2007), Pierre and Scarpetta (2004), Wasmer (2006) and Acharya, Baghai, and Subramanian (2014) among others show that employment protection can have positive effects on productivity.
} 
matching markets, where the time to find an appropriate trading partner depends on the ratio of buyers to sellers in the market, and where prices are negotiated bilaterally. The interaction between labor and innovation market has the following implication. Employment protection induces firms to keep workers employed even if productivity has dropped. This increases firms' willingness to pay for product or process innovations in order to restore productivity. This increases the price for innovations, triggers entry of new start-ups and shifts economic activity towards firms specializing in process and product innovation. It hence increases the rate at which firms that are hit by a negative productivity shock can purchase the (process or product) innovation necessary to restore their productivity.

We calibrate our model to match aggregate US labor and product market statistics as well as aggregate firm exit and entry rates. We then take the calibrated model, introduce employment protection and show that the rate at which firms are able to restore their productivity increases. Our comparative static results are also in line with the estimated negative impact of wrongful dismissal laws on productivity found by Autor, Kerr, and Kugler (2007) and the positive effect on innovations shown by Acharya, Baghai, and Subramanian (2014). Both exploit the fact that from 1970 to 199913 US states introduced wrongful dismissal laws by recognizing the so-called "good-faith" exception to the employment-at-will doctrine. Our calibration results are also consistent with the findings by Acharya, Baghai, and Subramanian (2014), who show that the adoption of wrongful dismissal laws increases the number of firms, especially start-ups. We also find evidence for a shift in economic activity. More presicely we find that the number of firms producing the final consumption good decreases while the number of firms specializing in producing machinery (process innovation) or product ideas (product innovation) increases. These results can reconcile the findings by Autor, Kerr, and Kugler (2007), who observe an increase in employment in the manufacturing sector, with the findings by Autor, Donohue, and Schwab (2006), who find a negative effect on state-level employment.

The papers that are most closely related to ours are Wasmer (2006) and Bartelsman, Gautier, and De Wind (2010). Both papers investigate the effect of employment protection in an equilibrium matching model to explain differences between the United States 
and continental Europe. Wasmer (2006) investigates the effect employment protection has on the type of human capital investment undertaken in the economy. The main difference to our framework is that he models productivity shocks as exogenous, while we endogenize the rate at which firms are able to restore their productivity. Bartelsman, Gautier, and De Wind (2010) consider an equilibrium matching model where, under employment protection, firms are less likely to adopt a high-risk and high-return technology and more likely to adopt a low-risk and save technology. The main difference to our model is that they do not consider that employment protection can increase the returns to investment in innovation.

Section 2 is the theory part of this paper; the calibration is done in section 3 . In the theory section, we first present the framework, derive the value functions for workers and firms and present the bargaining setup for the labor and the innovation market (sections 2.1 to 2.3 ). In section 2.4 , we derive the vacancy creation and firing conditions, present the wage outcomes, the innovation price and determine the specialization decision of

firms. Section 2.5 analyzes the steady-state flows of firms and workers and section 2.6 presents the equilibrium. Section 3.1 discusses our parameter choices for the calibration. In sections 3.3 and 3.4 we discuss the effects of the introduction of employment protection first without and then with the channel of the innovation market. Section 4 concludes.

\section{Theory}

\subsection{Framework}

The model has an infinite horizon, is set in continuous time and concentrates on steady states. All agents are risk neutral and discount the future at rate $r$. The economy is populated by a unit mass of homogenous workers and an endogenous mass $m$ of firms.

Production of consumption goods requires labor $N_{i} \in R_{0}^{+}$and the input $y_{i} \in\{0, y\}$, where $y_{i}$ can be interpreted as the productivity of the capital, which the firm employs, or the profitability of the firm's product in the market. The production function for consumption goods is given by $y_{i} F\left(N_{i}\right)=y_{i} N^{\alpha}$. All firms, which produce consumption 
goods, produce the same homogenous good with prices normalized to unity.

The input $y$, i.e., the product idea or the machinery, can be produced by each firm at its firm-specific innovation cost $k_{i}$. The per period cost $k_{i}$ is drawn randomly from a distribution characterized by the pdf $\gamma(k)$ and the cdf $\Gamma(k)$ on the support $\left[0, k_{\max }\right]$. We will also refer to the input $y$ as an innovation. It can be thought of both, a process innovation (machinery) or a product innovation. The research process underlying the production of the input $y$ is stochastic and happens at the Poisson rate $\eta$. It requires no production workers. The innovation $y$ is assumed to be destroyed by a productivity shock at the exogenous rate $\delta$. Thus, $1 / \delta$ can be interpreted as a product's or machinery's life-cycle.

Firms choose to become one of the following types $t \in\{B, R, S\}$ depending on the firm-specific innovation costs $k_{i}$. Type $B$ and type $R$ firms with $y_{i}=y$ produce the consumption good. Type $B$ firms, which have been hit by a productivity shock, i.e., $y_{i}=0$, search the innovation market for a new product or process innovation to restore their $y_{i}$ to $y$. The details of the innovation market are given below. Type $R$ firms, which are hit by a productivity shock, do their own research to restore their $y_{i}$ to $y$. For simplicity we assume that firms cannot innovate while producing consumption goods. Type $S$ firms develop product ideas or produce capital goods (machinery), i.e., they produce the input $y$ at rate $\eta$. Once they have produced the input $y$, they will sell it on the innovation market. Again, we assume for simplicity that they cannot produce $y$ while they are busy with selling the input $y$ in the innovation market.

The innovation market or market for new product ideas is characterized by matching frictions, with a constant return to scale matching function that satisfies the usual Inada conditions. Tightness in the innovation market is defined as the ratio of firms looking for a new machine or a product idea ( $B$ for buyers) to the firms that specialize in innovation and sell the input $y$ on the innovation market ( $S$ for sellers), i.e., $\varphi=B / S$. Firms that sell the innovation $y$ are matched at rate $\varphi g(\varphi)$ with buyers (type $B$ firms) and type $B$ firms contact sellers (type $S$ firms) at rate $g(\varphi)$. The properties of the matching function are such that the matching probability of a seller (buyer) increases (decreases) with the ratio 
of buyers to sellers, i.e., $[\varphi g(\varphi)]^{\prime}>0$ and $g^{\prime}(\varphi)<0$. The innovation price is determined by Nash-bargaining where $\beta$ denotes the bargaining power of sellers.

Innovation or research costs are firm-specific and set at the beginning of a firm's life. Formally, we assume that potential firms have to pay a cost $F$ upon entry (sufficiently small to guarantee existence) in order to learn the per-period, firm-specific innovation $\operatorname{cost} k_{i}$. For simplicity, we assume that new firms are born with input $y_{i}=y$ upon paying the entry cost $F$.

The interaction between the destruction of firms and the layoff decision for workers is modelled as follows. Type $B$ and type $R$ firms will consider laying off workers only if the firm was hit by a productivity shock $\delta$. A firm that decides to lay off workers will have to pay a firing cost $f$ per worker. Firms can be destroyed only if they were hit by a productivity shock, i.e., if $y_{i}=0$. Consumption good producers $(t=B$ or $t=R)$ with $y_{i}=0$ can be hit by a destruction shock at rate $\lambda_{d}$. If workers must be laid off, because a firm is insolvent and destroyed, no firing costs are due. Type $S$ firms that specialize in innovation do not employ production workers and therefore are not affected by firing costs. They are hit by a destruction shock at rate $\lambda_{s}$. We assume $\lambda_{s}<\lambda_{d}$, in order to ensure that type $S$ and type $B$ and $R$ firms are equally likely to be destroyed. The reason is that type $S$ firms are not only in the " $y_{i}=0 "$ state if they are hit by a productivity shock, but also when they are doing research in order to produce the innovation $y$. They are hence more often exposed to a destruction shock than type $B$ and $R$ firms.

The labor market for production workers is also modeled using matching frictions. Firms hire workers by posting vacancies at the per period cost $c$ (sufficiently small to guarantee existence). The matching function for production workers has constant return to scale and satisfies the Inada conditions. Labor market tightness is denoted by $\theta=$ $V / U$, where $V$ equals the number of vacancies created by all firms and $U$ the number of unemployed workers. The job finding rate of workers is given by $\theta \lambda_{m}(\theta)$ and the rate at which firms contact workers by $\lambda_{m}(\theta)$. The properties of the matching function are such that the matching probability of an unemployed worker (vacancy) increases (decreases) with the ratio of vacancies to unemployed, i.e., $\left[\theta \lambda_{m}(\theta)\right]^{\prime}>0$ and $\lambda_{m}^{\prime}(\theta)<0$. Wages are 
negotiated and renegotiated each time the productivity of a firm changes. The bargaining power of workers is denoted by $\gamma$. Unemployed workers receive unemployment benefits z. Employed workers receive a wage $w^{t}\left(y_{i}, N_{i}\right)$, which depends on $y_{i} \in\{0, y\}$, on the marginal product $y_{i} F^{\prime}\left(N_{i}\right)$, and the type $t$ of the firm.

\subsection{Value Functions}

\subsubsection{Workers}

Workers can become employed only at firms that produce consumption goods, since firms that specialize in innovation will not be active on the labor market for production workers. Firms will post vacancies and hire unemployed workers. Denote the fraction of vacancies posted by type $t \in\{B, R\}$ firms with productivity $y_{i}$ and $N_{i}$ employed workers by $v^{t}\left(y_{i}, N_{i}\right)$. We therefore can write the value of being unemployed as,

$$
r U=z+\theta \lambda_{m}(\theta) \sum_{t \in\{B, R\}, y_{i} \in\{0, y\}, N_{i}} \max \left[v^{t}\left(y_{i}, N_{i}\right) W^{O, t}\left(w^{O, t}\left(y_{i}, N_{i}\right)\right)-U, 0\right]
$$

where the value of being employed at a type $t$ firm as an outsider, that is, as a newly hired worker (indexed by $O$ ), at the wage $w^{O, t}\left(y, N_{i}\right)$ is given by,

$r W^{O, t}\left(w^{O, t}\left(y, N_{i}\right)\right)=w^{O, t}\left(y, N_{i}\right)+\delta\left(\max \left[W^{I, t}\left(w^{I, t}\left(0, N_{i}\right)\right), U\right]-W^{O, t}\left(w^{O, t}\left(y, N_{i}\right)\right)\right)$.

Once a worker is employed, he becomes an insider, indexed by $I$, and has employment protection. This protection (manifested through firing costs) implies that insiders will receive a higher wage when wages are renegotiated. The value of being employed as an insider at a firm with $y_{i}=y$ is given by,

$$
r W^{I, t}\left(w^{I, t}\left(y, N_{i}\right)\right)=w^{I, t}\left(y, N_{i}\right)+\delta\left(\max \left[W^{I, t}\left(w^{I, t}\left(0, N_{i}\right)\right), U\right]-W^{I, t}\left(w^{I, t}\left(y, N_{i}\right)\right)\right)
$$

The value of being employed depends on whether the surplus of the match is negative if the firm is hit by a productivity shock. If it is, wage negotiations will fail and the worker will be laid off. However, if the surplus of a match is positive even if a productivity shock 
hits, then wages will be renegotiated and the value of being employed changes to,

$$
\begin{aligned}
& r W^{I, R}\left(w^{I, R}\left(0, N_{i}\right)\right)=\left\{\begin{array}{l}
w^{I, R}\left(0, N_{i}\right)+\eta\left(W^{I, R}\left(w^{I, R}\left(y, N_{i}\right)\right)-W^{I, R}\left(w^{I, R}\left(0, N_{i}\right)\right)\right) \\
+\lambda_{d}\left(U-W^{I, R}\left(w^{I, R}\left(0, N_{i}\right)\right)\right), \text { if } t=R,
\end{array}\right. \\
& r W^{I, B}\left(w^{I, B}\left(0, N_{i}\right)\right)=\left\{\begin{array}{l}
w^{I, B}\left(0, N_{i}\right)+g(\varphi)\left(W^{I, B}\left(w^{I, B}\left(y, N_{i}\right)\right)-W^{I, B}\left(w^{I, B}\left(0, N_{i}\right)\right)\right) \\
+\lambda_{d}\left(U-W^{I, B}\left(w^{I, B}\left(0, N_{i}\right)\right)\right), \text { if } t=B .
\end{array}\right.
\end{aligned}
$$

The value of being employed at a firm with $y_{i}=0$ depends on the wage, the type $t \in\{B, R\}$ of a firm, the respective rate at which the firm is able to restore $y_{i}$ to $y$, that is, $\eta$ for firms that do their own research and $g(\varphi)$ for firms that buy the innovation, and on the destruction rate $\lambda_{d}$.

\subsubsection{Firms}

Firms producing consumption goods, i.e., type $t \in\{B, R\}$ firms, choose their labor input by deciding on the number of vacancies $V_{i}^{t}$ they want to post and the number of workers they want to lay off $L_{i}^{t}$. The equation governing the change in the number of workers employed at firm $i$ that posts vacancies $V_{i}^{t}$ and lays off $L_{i}^{t}$ workers is given by,

$$
\dot{N}_{i}^{t}=\lambda_{m}(\theta) V_{i}^{t}-L_{i}^{t}
$$

Thus, firms only need to post vacancies, when they want to hire new workers (in which case $V_{i}^{t}>0$ and $L_{i}^{t}=0$ ). If they want to lay off workers, they will post no vacancies, i.e., $L_{i}^{t}>0$ and $V_{i}^{t}=0$. Firms that want to start production will immediately hire their optimal number of workers $N_{i}^{t}$, by posting $V_{i}^{t}=N_{i}^{t} / \lambda_{m}(\theta)$ vacancies. If a firm wants to lay off workers, it will either lay off all workers or keep all workers, i.e., $L_{i}^{t} \in\left\{0, N_{i}^{t}\right\}$, since firing costs per worker are constant and the marginal revenue product equals zero in case a productivity shock hits.

We denote the expected profit of a type $t \in\{S, B, R\}$ firm with $y_{i}=y, N_{i}^{t}$ workers, and innovation cost $k_{i}$ by $\pi^{O, t}\left(N_{i}^{t}, y_{i}, k_{i}\right)$, where the index $O$ for outsider is used every time the firm has hired new workers. A new firm has to decide which type it wants to be, 
i.e.,

$$
\max _{t \in\{S, B, R\}} \pi^{O, t}\left(N_{i}^{t}, y, k_{i}\right)-\frac{c}{\lambda_{m}(\theta)} N_{i}^{t}
$$

where $c N_{i}^{t} / \lambda_{m}(\theta)$ equals the expected cost of hiring a worker, that is, the vacancy posting cost $c$ times the number of vacancies it posts $V_{i}^{t}=N_{i}^{t} / \lambda_{m}(\theta)$ in order to hire $N_{i}^{t}$ workers.

Firms that specialize in innovation will not be active on the labor market for production workers, i.e., $N_{i}^{S}=0$. Thus, labor market conditions only enter the expected profit of a selling firm via the prices it receives for its innovation. The expected profit of a type $S$ firm that is doing research to obtain a new innovation is given by,

$$
\left(r+\lambda_{s}\right) \pi^{S}\left(0,0, k_{i}\right)=-k_{i}+\eta\left(\pi^{S}\left(0, y, k_{i}\right)-\pi^{S}\left(0,0, k_{i}\right)\right)
$$

The expected profit of a type $S$ firm, which sells its innovation,is given by,

$$
\begin{aligned}
r \pi^{S}\left(0, y, k_{i}\right) & =\varphi g(\varphi) \max \left[E_{N_{j}}\left[p\left(k_{i}, N_{j}^{B}\right)\right]+\pi^{S}\left(0,0, k_{i}\right)-\pi^{S}\left(0, y, k_{i}\right), 0\right] \\
& +\delta\left(\pi^{S}\left(0,0, k_{i}\right)-\pi^{S}\left(0, y, k_{i}\right)\right)
\end{aligned}
$$

where the price $p\left(k_{i}, N_{j}^{B}\right)$ that is negotiated on the innovation market will depend on the surplus that is generated. The surplus will depend on the innovation cost $k_{i}$ of the seller and the number of workers employed at the buyer $N_{j}^{B}$. The buyer's innovation cost does not enter the surplus, since a firm that decided to buy the input $y$ will also do so in the future, that is, it will never decide to do own research. Sellers only sell their innovation when the surplus is positive.

The following Bellman equation characterizes the expected profit of a type $B$ or $R$ firm with $y_{i}=y$ and innovation cost $k_{i}$, that chooses its workforce $N_{i}^{t}$ optimally, i.e.,

$$
\begin{aligned}
r \pi^{h, t}\left(N_{i}^{t}, y, k_{i}\right) & =\max _{N_{i}^{t}} y\left(N_{i}^{t}\right)^{\alpha}-w^{h, t}\left(y, N_{i}^{t}\right) N_{i}^{t} \\
& +\delta\left(\max \left[\pi^{I, t}\left(N_{i}^{t}, 0, k_{i}\right), \pi^{O, t}\left(0,0, k_{i}\right)-f N_{i}^{t}\right]-\pi^{h, t}\left(N_{i}^{t}, y, k_{i}\right)\right),
\end{aligned}
$$

for $t \in\{B, R\}$ and subject to equation (6). Note, that this equation holds for all type $B$ or $R$ firms regardless of whether they employ outsiders $h=O$ or have insiders $h=I$. Firms that decide not to layoff their workers once a productivity shock $\delta$ hits, i.e., $L_{i}^{t}=0$, can renegotiate the wage with their current workforce (insiders), i.e., have a continuation value 
$\pi^{I, t}\left(N_{i}^{t}, 0, k_{i}\right)$. Firms that decide to layoff their workers, i.e., $L_{i}^{t}=N_{i}^{t}$, have to continue without workers, which implies a continuation value $\pi^{O, t}\left(0,0, k_{i}\right)$ and the payment of $f N_{i}^{t}$ of firing costs.

The Bellman equations for a type $R$ firm that decides to do own research when it was hit by a productivity shock are given by,

$$
\begin{aligned}
\left(r+\lambda_{d}\right) \pi^{O, R}\left(0,0, k_{i}\right) & =-k_{i}+\eta\left(\pi^{O, R}\left(N_{i}^{R}, y, k_{i}\right)-\frac{c}{\lambda_{m}(\theta)} N_{i}^{R}-\pi^{O, R}\left(0,0, k_{i}\right)\right) \\
\left(r+\lambda_{d}\right) \pi^{I, R}\left(N_{i}^{R}, 0, k_{i}\right) & =-w^{I, R}\left(0, N_{i}^{R}\right) N_{i}^{R}-k_{i}+\eta\left(\pi^{I, R}\left(N_{i}^{R}, y, k_{i}\right)-\pi^{I, R}\left(N_{i}^{R}, 0, k_{i}\right)\right)
\end{aligned}
$$

with and without laying off workers, respectively. A type $B$ firm that decides to acquire an innovation when it is without one has the following expected profit,

$$
\begin{aligned}
\left(r+\lambda_{d}\right) \pi^{O, B}\left(0,0, k_{i}\right) & =g(\varphi) \int_{0}^{k_{\max }} \max \left[S^{B}, 0\right] h\left(k_{j}\right) d k_{j}, \\
\left(r+\lambda_{d}\right) \pi^{I, B}\left(N_{i}^{B}, 0, k_{i}\right) & =-w^{I, B}\left(0, N_{i}^{B}\right) N_{i}^{B}+g(\varphi) \int_{0}^{k_{\max }} \max \left[S^{B}, 0\right] h\left(k_{j}\right) d k_{j},
\end{aligned}
$$

with and without laying off workers, respectively, where the surplus for the buyer is given by,

$$
S^{B}=\left\{\begin{array}{l}
\pi^{O, B}\left(N_{i}^{B}, y, k_{i}\right)-\frac{c}{\lambda_{m}(\theta)} N_{i}^{B}-\pi^{O, B}\left(0,0, k_{i}\right)-p\left(k_{j}, 0\right) \text { if } L_{i}^{B}=N_{i}^{B}, \\
\pi^{I, B}\left(N_{i}^{B}, y, k_{i}\right)-\pi^{I, B}\left(N_{i}^{B}, 0, k_{i}\right)-p\left(k_{j}, N_{i}^{B}\right) \text { if } L_{i}^{B}=0 .
\end{array}\right.
$$

The decision whether to do own research or, instead, acquire an innovation depends on the rate $\eta$ or $g(\varphi)$ at which the firm can restore its productivity level, on the level of firm-specific innovation cost $k_{i}$, and the expected price of the innovation. Since a firm can buy an innovation only from firms that decide to sell their innovations, we denote by $h\left(k_{j}\right)$ the pdf of those firms that are willing to sell their innovations and that have innovation cost $k_{j}$ (in equilibrium $h\left(k_{j}\right)=\gamma\left(k_{j}\right) / \Gamma\left(k^{*}\right)$, since all firms with $k_{j}$ below some threshold $k^{*}$ prefer to specialize in innovation and are willing to sell their innovations). The maximum operator in the integral guarantees that firms will buy an innovation only when the surplus is positive. 


\subsection{Bargaining}

\subsubsection{Bargaining in the Innovation Market}

The value of a type $B$ firm that decides to acquire an innovation, depends on the number of workers it employs $N_{i}^{B}$, and the value of a type $S$ firm that sells an innovation depends on the innovation cost $k_{j}$. These two factors determine the innnovation price, which can be obtained solving for the Nash-product,

$$
\begin{aligned}
p\left(k_{j}, 0\right) & =\arg \max _{p}\left(\pi^{O, B}\left(N_{i}^{B}, y, k_{i}\right)-\frac{c}{\lambda_{m}(\theta)} N_{i}^{B}-\pi^{O, B}\left(0,0, k_{i}\right)-p\right)^{1-\beta} \\
& \times\left(p+\pi^{S}\left(0,0, k_{j}\right)-\pi^{S}\left(0, y, k_{j}\right)\right)^{\beta} \\
p\left(k_{j}, N_{i}^{B}\right) & =\arg \max _{p}\left(\pi^{I, B}\left(N_{i}^{B}, y, k_{i}\right)-\pi^{I, B}\left(N_{i}^{B}, 0, k_{i}\right)-p\right)^{1-\beta} \\
& \times\left(p+\pi^{S}\left(0,0, k_{j}\right)-\pi^{S}\left(0, y, k_{j}\right)\right)^{\beta}
\end{aligned}
$$

where the surplus of a firms that buys an innovation is given by the increase in expected profits from restoring $y_{i}$ from 0 to $y$ minus the price, and the surplus of an firm that sells the innovation is given by the price plus the expected loss in profit from giving up the innovation.

\subsubsection{Bargaining in the Labor Market}

Wages in the labor market are also determined by Nash-bargaining. We assume intrafirm bargaining as in Smith (1999), Cahuc and Wasmer (2001), and Cahuc, Marque, and Wasmer (2008), among others. The worker surplus equals the value of being employed minus the outside option of being unemployed. The firm's surplus depends on whether it bargains with outsiders (new workers) or with insiders. If a firm is bargaining with outsiders the surplus is given by the marginal value of an additional worker. If an old firm is renegotiating the wages of its current workfore (insiders), then the surplus of continuing the employment relationship is given by the marginal value of an additional worker plus the firing cost $f$, since a bargaining agreement ensures that the firm does not have to pay the firing cost. The Nash-product in the event a firm negotiates with 
outsiders and insiders, respectively, is given by,

$$
\begin{aligned}
& w^{O, t}\left(y_{i}, N_{i}^{t}\right)=\arg \max _{w}\left(W^{O, t}(w)-U\right)^{\gamma}\left(\frac{\partial \pi^{O, t}\left(N_{i}^{t}, y_{i}, k_{i}\right)}{\partial N_{i}^{t}}\right)^{1-\gamma}, \\
& w^{I, t}\left(y_{i}, N_{i}^{t}\right)=\arg \max _{w}\left(W^{I, t}(w)-U\right)^{\gamma}\left(\frac{\partial \pi^{I, t}\left(N_{i}^{t}, y_{i}, k_{i}\right)}{\partial N_{i}^{t}}+f\right)^{1-\gamma} .
\end{aligned}
$$

The bargaining wage $w^{t}\left(y_{i}, N_{i}^{t}\right)$ will depend on the type $t \in\{B, R\}$ that a firm with innovation cost $k_{i}$ chooses, on the number of workers it employs $N_{i}^{t}$, and on $y_{i} \in\{0, y\}$.

\subsection{Optimality Conditions}

\subsubsection{Vacancy Creation Condition}

Type $B$ or $R$ firms will post vacancies until the marginal value of an additional worker equals the expected cost of hiring a worker, i.e.,

$$
\frac{\partial \pi^{O, t}\left(N_{i}^{t}, y, k_{i}\right)}{\partial V_{i}^{t}}=0 \Longrightarrow \frac{\partial \pi^{O, t}\left(N_{i}^{t}, y, k_{i}\right)}{\partial N_{i}^{t}}=\frac{c}{\lambda_{m}(\theta)} .
$$

Thus, if the marginal value of an additional worker for a type $B$ firm is different than that of a type $R$ firm, then the number of vacancies posted and the number of workers employed will be different too.

The marginal value of an additional worker for a firm with $y_{i}=y$ that wants to hire new workers $(h=O)$ is given by differentiating equation (9). The value depends on whether a firm lays off workers when it is hit by a productivity shock, i.e.,

$$
\frac{\partial \pi^{O, t}\left(N_{i}^{t}, y, k_{i}\right)}{\partial N_{i}^{t}}= \begin{cases}\frac{\alpha y\left(N_{i}^{t}\right)^{\alpha-1}-w^{O, t}\left(y, N_{i}^{t}\right)-\frac{\partial w^{O, t}\left(y, N_{i}^{t}\right)}{\partial N_{i}^{t}} N_{i}^{t}+\delta \frac{\partial \pi^{I, t}\left(N_{i}^{t}, 0, k_{i}\right)}{\partial N_{i}^{t}}}{r+\delta} & \text { if } L_{i}^{t}=0, \\ \frac{\alpha y\left(N_{i}^{t}\right)^{\alpha-1}-w^{O, t}\left(y, N_{i}^{t}\right)-\frac{\partial w^{O, t}\left(y, N_{i}^{t}\right)}{\partial N_{i}^{t}} N_{i}^{t}-\delta f}{r+\delta} & \text { if } L_{i}^{t}=N_{i}^{t},\end{cases}
$$

The third term in the marginal value of an additional worker $\left(\partial w^{O, t}\left(y, N_{i}^{t}\right) / \partial N_{i}^{t}\right) N_{i}^{t}$ captures the fact that each time a new worker is hired, the wages of all workers are renegotiated and adjusted to the new marginal revenue product. 
The marginal value of an additional worker for a firm, which has been hit by a productivity shock but retains its workers, will be positive, if the rate at which the firm can restore its productivity is high enough. The marginal value can be obtained by differentiating equations (11) and (13) and using equation (45) to substitute out the price for an innovation (see Appendix A.3). Substituting the vacancy creation condition (16) implies,

$$
\frac{\partial \pi^{I, t}\left(N_{i}^{t}, 0, k_{i}\right)}{\partial N_{i}^{t}}=\left\{\begin{array}{l}
\frac{\eta}{r+\lambda_{d}+\eta}\left(\frac{c}{\lambda_{m}(\theta)}-\gamma f-\frac{w^{I, R}\left(0, N_{i}^{R}\right)}{\eta}\right) \text { if } t=R, \\
\frac{g(\varphi)}{r+\lambda_{d}+g(\varphi)(1-\beta)}\left((1-\beta)\left(\frac{c}{\lambda_{m}(\theta)}-\gamma f\right)-\frac{w^{I, B}\left(0, N_{i}^{B}\right)}{g(\varphi)}\right) \\
\text { if } t=B .
\end{array}\right.
$$

The marginal value of an additional worker is negative only if the wage payments over the expected duration until the firm obtains a new innovation, i.e., $1 / \eta$ or $1 / g(\varphi)$, are higher than the expected cost of hiring a worker $c / \lambda_{m}(\theta)$ minus the part of the firing cost that the firm would have to bear $\gamma f$ if it lays off a worker (or the fraction $(1-\beta)$ for type $B$ firms due to Nash-bargaining). If the rate at which a firm can restore its productivity, i.e., $\eta$ or $g(\varphi)$, is sufficiently high, the marginal value of an additional worker is positive.

The first-order condition for the optimal number of posted vacancies shows that vacancy posting costs always exceeds the marginal value of an additional worker for a firm that has been hit by a productivity shock, i.e.,

$$
\frac{\partial \pi^{t}\left(N_{i}^{t}, 0, k_{i}\right)}{\partial V_{i}^{t}}=\frac{\partial \pi^{t}\left(N_{i}^{t}, 0, k_{i}\right)}{\partial N_{i}^{t}} \lambda_{m}(\theta)-c<0,
$$

as one can easily verify by substituting the marginal value of an additional worker using equation (18). Thus, firms that have been hit by a productivity shock never post vacancies.

\subsubsection{Firing Condition}

Firms hit by a productivity shock $\delta$ consider whether to lay off workers. Since the marginal value of an additional worker for a firm that has been hit by a productivity shock is independent of the number of employed workers - as stated in equation (18) - it is optimal for a firm to either keep all its workers, when the surplus is positive, that is, if 
the marginal value of a worker plus the firing cost is positive, or to lay off all workers when the surplus is negative, that is,

$$
L_{i}^{t}=\left\{\begin{array}{l}
0, \quad \text { if } \frac{\partial \pi^{I, t}\left(N_{i}^{t}, 0, k_{i}\right)}{\partial N_{i}^{t}}+f \geq 0, \\
N_{i}^{t}, \quad \text { if } \frac{\partial \pi^{I, t}\left(N_{i}^{t}, 0, k_{i}\right)}{\partial N_{i}^{t}}+f<0 .
\end{array}\right.
$$

Note, that the marginal value of an additional worker for a firm that has been hit by a productivity shock depends on the rate at which it can restore its productivity. Thus, employment protection will only ensure that workers are not laid off, if the rate at which the productivity can be restored is sufficiently high.

\subsubsection{Wages}

Wages are determined by Nash-bargaining according to the surplus splitting rule of equation (14). All wage equations below are derived in Appendix A.1.

We consider first the situation in which workers are not laid off if a firm is hit by a productivity shock, i.e., $L_{i}^{t}=0$. The wages paid to outsiders and insiders at type $R$ firms with $y_{i}=y$ are given by,

$$
\begin{aligned}
& w^{O, R}\left(y, N_{i}^{R}\right)=(1-\gamma) z+\gamma \theta c+\gamma \frac{\alpha}{1-\gamma(1-\alpha)} y\left(N_{i}^{R}\right)^{\alpha-1}-\gamma \delta f \\
& w^{I, R}\left(y, N_{i}^{R}\right)=(1-\gamma) z+\gamma \theta c+\gamma \frac{\alpha}{1-\gamma(1-\alpha)} y\left(N_{i}^{R}\right)^{\alpha-1}+\gamma r f
\end{aligned}
$$

Insiders will receive a higher wage than outsiders because firms' outside option during bargaining is lower once they have to renegotiate with insiders, who are protected by firing costs. Thus, outsiders will receive a lower wage initially in return for a higher wage later on. The wages at type $B$ firms include an additional term that accounts for the fact that part of the firm's surplus is going to the seller (type $S$ firm) for the purchase of the innovation, i.e.,

$$
\begin{aligned}
w^{O, B}\left(y, N_{i}^{B}\right) & =(1-\gamma) z+\gamma \theta c+\gamma \frac{\alpha}{1-\gamma(1-\alpha)} y\left(N_{i}^{B}\right)^{\alpha-1}-\gamma \delta f \\
& +\delta \beta g(\varphi) \gamma \frac{g(\varphi)(1-\beta)\left(\frac{c}{\lambda_{m}(\theta)}-\gamma f\right)-w^{I, B}\left(0, N_{i}^{B}\right)}{\left(r+\lambda_{d}+g(\varphi)\right)\left(r+\lambda_{d}+g(\varphi)(1-\beta)\right)}
\end{aligned}
$$




$$
\begin{aligned}
w^{I, B}\left(y, N_{i}^{B}\right) & =(1-\gamma) z+\gamma \theta c+\gamma \frac{\alpha}{1-\gamma(1-\alpha)} y\left(N_{i}^{B}\right)^{\alpha-1}+\gamma r f \\
& +\delta \beta g(\varphi) \gamma \frac{g(\varphi)(1-\beta)\left(\frac{c}{\lambda_{m}(\theta)}-\gamma f\right)-w^{I, B}\left(0, N_{i}^{B}\right)}{\left(r+\lambda_{d}+g(\varphi)\right)\left(r+\lambda_{d}+g(\varphi)(1-\beta)\right)}
\end{aligned}
$$

Firms, which are hit by a productivity shock, i.e., $y_{i}=0$, that keep their workers, i.e., $L_{i}^{t}=0$, pay the following wages,

$$
\begin{aligned}
& w^{I, R}\left(0, N_{i}^{R}\right)=(1-\gamma) z+\gamma \theta c+\gamma\left(r+\lambda_{d}\right) f \\
& w^{I, B}\left(0, N_{i}^{B}\right)=(1-\gamma) z+\gamma \theta c-\beta g(\varphi) \gamma\left(\frac{c}{\lambda_{m}(\theta)}+(1-\gamma) f\right)+\gamma\left(r+\lambda_{d}\right) f
\end{aligned}
$$

A type $R$ firm pays a wage $w^{I, R}\left(0, N_{i}^{R}\right)$ which equals workers' flow value of being unemployed plus a certain fraction of the firing costs, which reflects the worse ouside option of firms when bargaining with insiders. If workers are employed at a type $B$ firm, then part of the surplus, which the firm has to pay to the seller of the innovation, must be borne by its workers.

If firms lay off their workforce when they are hit by a productivity shock, then workers do not have a chance to renegotiate their wages as insiders. This implies that there will be only one wage, if $L_{i}^{t}=N_{i}^{t}$. The fact that workers are paid only the outsider wage can also be seen by noting that the workers' value of being employed in equation (2) simplifies, since $\max \left[W^{I, t}\left(w^{I, t}\left(0, N_{i}\right)\right), U\right]=U$. The respective wage is therefore given by,

$$
w^{O, t}\left(y, N_{i}^{t}\right)=(1-\gamma) z+\gamma \theta c+\gamma \frac{\alpha}{1-\gamma+\gamma \alpha} y\left(N_{i}^{t}\right)^{\alpha-1}-\gamma \delta f, \text { all for } t \in\{B, R\}
$$

Note, that the wage in this case is independent of the type of a firm, since the vacancy creation conditions and therefore the level of employment are identical.

\subsubsection{Innovation Prices}

The vacancy creation and firing conditions (16) and (19) imply that in a given steady state, all type $B$ firms have either 0 or $N_{j}^{B}$ employees. This simplifies the analysis and implies that the expected price of an innovation charged by a firm with innovation cost $k_{i}$ is given by $p\left(k_{i}, 0\right)$ or $p\left(k_{i}, N_{j}^{B}\right)$. Since we concentrate on the parameter sets that guarantee the 
existence of an innovation market, we know that all type $S$ firms are willing to sell to any type $B$ firm, that is, all matches in the innovation market will generate a positive surplus.

To derive a closed-form solution for the innovation price we need closed form expressions for the expected profits of type $B$ and type $R$ firms. The closed-form expressions can be found in Appendix A.4. To determine the price that type $B$ firms expect to pay for an innovation, we first focus on the average seller that has innovation cost $\bar{k}$ such that its price equals the expected price, i.e.,

$$
p\left(\bar{k}, N_{i}^{B}\right)=E_{k_{j}}\left[p\left(k, N_{i}^{B}\right)\right] \text { or } p(\bar{k}, 0)=E_{k_{j}}[p(k, 0)] .
$$

In Appendix A.4 we derive the following expression for the expected innovation price,

$$
\begin{aligned}
& E_{k_{j}}\left[p\left(\bar{k}, N_{i}^{B}\right)\right]=\frac{K_{2} \beta\left(r+\lambda_{d}\right)\left(y\left(N_{i}^{B}\right)^{\alpha}-w^{B}\left(y, N_{i}^{B}\right) N_{i}^{B}\right)+K_{2} \beta r w^{I, B}\left(0, N_{i}^{B}\right) N_{i}^{B}}{K_{1} K_{2}-K_{1}(1-\beta)\left(r+\lambda_{s}\right) \varphi g(\varphi)-K_{2} \beta r g(\varphi)} \\
& +\frac{K_{1}(1-\beta) r \bar{k}}{K_{1} K_{2}-K_{1}(1-\beta)\left(r+\lambda_{s}\right) \varphi g(\varphi)-K_{2} \beta r g(\varphi)} \\
& E_{k_{j}}[p(\bar{k}, 0)]=\frac{K_{2} \beta\left(r+\lambda_{d}\right)\left(y\left(N_{i}^{B}\right)^{\alpha}-w^{O, B}\left(y, N_{i}^{B}\right) N_{i}^{B}-\delta f N_{i}^{B}-(r+\delta) \frac{c}{\lambda_{m}(\theta)} N_{i}^{B}\right)}{K_{1} K_{2}-K_{1}(1-\beta)\left(r+\lambda_{s}\right) \varphi g(\varphi)-K_{2} \beta r g(\varphi)} \\
& +\frac{K_{1}(1-\beta) r \bar{k}}{K_{1} K_{2}-K_{1}(1-\beta)\left(r+\lambda_{s}\right) \varphi g(\varphi)-K_{2} \beta r g(\varphi)},
\end{aligned}
$$

where

$$
\begin{aligned}
& K_{1}=(r+\delta)\left(r+\lambda_{d}\right)+r g(\varphi), \\
& K_{2}=(r+\delta+\varphi g(\varphi))\left(r+\lambda_{s}\right)+r \eta
\end{aligned}
$$

The explicit formulas for the innovation prices $p\left(k_{j}, N_{i}^{B}\right)$ or $p\left(k_{j}, 0\right)$ for any firm-specific innovation cost $k_{j}$ are very similar. They can be found in Appendix A.4.

\subsubsection{Type Choice}

Given the innovation cost $k_{i}$ new firms must decide on their type $t \in\{S, R, B\}$. We concentrate on an equilibrium in which all three types exist. Of course there are parameter 
values where only $S$ and $B$ type firms exist (for $\eta$ sufficiently small), and parameter values where only type $R$ firms exist (for $\eta$ sufficiently high).

Type $B$ firms decide to buy an innovation when they are hit by a productivity shock. They therefore never innovate. Their expected profits hence are independent of $k_{i}$. Thus, the minimum profit that each firm can obtain is given by the expected profit of type $B$ firms (before they hire workers), i.e.,

$$
\pi^{O, B}\left(N_{i}^{B}, y, k_{i}\right)-\frac{c}{\lambda_{m}(\theta)} N_{i}^{B}
$$

where $\pi^{O, B}\left(N_{i}^{B}, y, k_{i}\right)$ is given by equation (48) or (50) in Appendix A.4 for $L_{i}^{B}=0$ and $L_{i}^{B}=N_{i}^{B}$, respectively. Type $R$ firms that do their own research when they are hit by a productivity shock have the following expected profit (before they hire workers),

$$
\pi^{O, R}\left(N_{i}^{R}, y, k_{i}\right)-\frac{c}{\lambda_{m}(\theta)} N_{i}^{R}
$$

where the closed form expressions for $\pi^{O, R}\left(N_{i}^{R}, y, k_{i}\right)$ for firms that retain their workers and for firms that lay off their workers are given in Appendix A.5. Type $S$ firms that innovate only in order to sell their innovations obtain the expected profit $\pi^{S}\left(0, y, k_{i}\right)$. In Appendix A.5 we derive the respective closed form expressions, where we substitute the price $p\left(k_{i}, N\right)$ for the product idea.

Firms that specialize in innovation do more research and their profits are therefore more sensitive to the cost of innovation $k_{i}$. In Appendix A.5 we formally show that the expected profit of type $S$ firms decreases more in the cost of innovation $k_{i}$ than the expected profit of type $R$ firms, i.e.,

$$
\frac{\partial \pi^{S}\left(0, y, k_{i}\right)}{\partial k_{i}}<\frac{\partial \pi^{O, R}\left(N_{i}^{R}, y, k_{i}\right)}{\partial k_{i}}<\frac{\partial \pi^{O, B}\left(N_{i}^{B}, y, k_{i}\right)}{\partial k_{i}}=0 .
$$

Given this single crossing property we can define the innovation cost thresholds $k^{*}$ and $k^{* *}$. Thus, firms with innovation cost $k_{i} \in\left[0, k^{*}\right]$ will specialize in innovation, firms with innovation cost $k_{i} \in\left(k^{*}, k^{* *}\right)$ will do their own research if they are hit by a productivity shock, and firms with innovation cost $k_{i} \in\left[k^{* *}, k_{\max }\right]$ will buy a new innovation when they need one. This also implies that $h\left(k_{i}\right)=\gamma\left(k_{i}\right) / \Gamma\left(k^{*}\right)$. The thresholds are formally 
defined by the following indifference conditions for type $S$ and type $R$ firms (thresholds $k^{*}$ ) and type $R$ and type $B$ firm (thresholds $k^{* *}$ ) respectively,

$$
\begin{array}{r}
\pi^{S}\left(0, y, k^{*}\right)=\pi^{O, R}\left(N_{i}^{R}, y, k^{*}\right)-\frac{c}{\lambda_{m}(\theta)} N_{i}^{R}, \\
\pi^{O, R}\left(N_{i}^{R}, y, k^{* *}\right)-\frac{c}{\lambda_{m}(\theta)} N_{i}^{R}=\pi^{O, B}\left(N_{i}^{B}, y, k^{* *}\right)-\frac{c}{\lambda_{m}(\theta)} N_{i}^{B} .
\end{array}
$$

Note that the appropriate equation for the expected profit depends on whether firms lay off workers if a productivity shock hits.

\subsubsection{Firm Entry}

The expected profit of a new firm before it draws its innovation cost $k_{i}$ determines the number $m$ of firms in the economy. Since the expected profits $\pi^{S}\left(0, y, k_{i}\right)$ and $\pi^{O, R}\left(N_{i}^{R}, y, k_{i}\right)$ are linear in $k_{i}$ and $\pi^{O, B}\left(N_{i}^{B}, y, k_{i}\right)$ independent of $k_{i}$, we can write the expected profit as,

$$
\begin{aligned}
F & =\Gamma\left(k^{*}\right) \pi^{S}(0, y, \bar{k}) \\
& +\left(\Gamma\left(k^{* *}\right)-\Gamma\left(k^{*}\right)\right)\left(\pi^{O, R}\left(N_{i}^{R}, y, \overline{\bar{k}}\right)-\frac{c}{\lambda_{m}(\theta)} N_{i}^{R}\right) \\
& +\left(1-\Gamma\left(k^{* *}\right)\right)\left(\pi^{O, B}\left(N_{i}^{B}, y, k_{i}\right)-\frac{c}{\lambda_{m}(\theta)} N_{i}^{B}\right),
\end{aligned}
$$

where average innovation cost $\bar{k}$ among type $S$ firms and $\overline{\bar{k}}$ among type $R$ firms are given by,

$$
\bar{k}=\int_{0}^{k^{*}} k_{i} \frac{\gamma\left(k_{i}\right)}{\Gamma\left(k^{*}\right)} d k_{i} \text { and } \overline{\bar{k}}=\int_{k^{*}}^{k^{* *}} k_{i} \frac{\gamma\left(k_{i}\right)}{\Gamma\left(k^{* *}\right)-\Gamma\left(k^{*}\right)} d k_{i} .
$$

Given the entry cost $F$, firms will enter until the expected profit is equal to the cost of entry. The parameter $m$ for the number of firms is not directly visible in the entry condition (31), but it enters the expected profit indirectly via the labor market tightness $\theta$. The steady state value of the labor market tightness are determined using the steady state flow equations analyzed in the next section. 


\subsection{Steady State Measures}

\subsubsection{Firm Flows and Innovation Market Tightness}

We denote the measure of type $t$ firms with $N_{i}^{t}$ employed workers and with $y_{i} \in\{0, y\}$ by $m^{t}\left(y_{i}, N_{i}^{t}\right)$. The number of firms must sum to $m$. Denote the measure of firms that exit the economy each period by $m^{e}$, where the assumptions regarding the destruction of firms imply,

$$
m^{e}=\lambda_{s} m^{S}(0,0)+\lambda_{d}\left(m^{R}\left(0, N_{i}^{R}\right)+m^{B}\left(0, N_{i}^{B}\right)\right)
$$

In a steady state the measure of firms that exit the economy is equal to the measure of new firms that enter, i.e., $m^{e}=m^{n}$. The respective measure of firms evolve according to the difference between in- and outflows, i.e.,

$$
\begin{aligned}
\dot{m}^{S}(0,0) & =(\delta+\varphi g(\varphi)) m^{S}(y, 0)-\left(\lambda_{s}+\eta\right) m^{S}(0,0) \\
\dot{m}^{S}(y, 0) & =\Gamma\left(k^{*}\right) m^{n}+\eta m^{S}(0,0)-(\delta+\varphi g(\varphi)) m^{S}(y, 0) \\
\dot{m}^{R}\left(0, N_{i}^{R}\right) & =\delta m^{R}\left(y, N_{i}^{R}\right)-\left(\lambda_{d}+\eta\right) m^{R}\left(0, N_{i}^{R}\right) \\
\dot{m}^{R}\left(y, N_{i}^{R}\right) & =\left(\Gamma\left(k^{* *}\right)-\Gamma\left(k^{*}\right)\right) m^{n}+\eta m^{R}\left(0, N_{i}^{R}\right)-\delta m^{R}\left(y, N_{i}^{R}\right) \\
\dot{m}^{B}\left(0, N_{i}^{B}\right) & =\delta m^{B}\left(y, N_{i}^{B}\right)-\left(\lambda_{d}+g(\varphi)\right) m^{B}\left(0, N_{i}^{B}\right) \\
\dot{m}^{B}\left(y, N_{i}^{B}\right) & =\left(1-\Gamma\left(k^{* *}\right)\right) m^{n}+g(\varphi) m^{B}\left(0, N_{i}^{B}\right)-\delta m^{B}\left(y, N_{i}^{B}\right)
\end{aligned}
$$

We focus on the steady state, where the measures of the different firm types do not change, i.e., $\dot{m}^{t}\left(y_{i}, N_{i}^{t}\right)=0$. The above flow equations allow us to write the ratio of the steady state measures of type $B$ firms $m^{B}\left(0, N_{i}^{B}\right)$ to the measure of type $S$ firms $m^{S}(y, 0)$ as follows,

$$
\varphi=\frac{m^{B}\left(0, N_{i}^{B}\right)}{m^{S}(y, 0)}=\frac{\lambda_{s}}{\lambda_{s}+\eta} \frac{\delta+\varphi g(\varphi)}{\lambda_{d}} \frac{1-\Gamma\left(k^{* *}\right)}{\Gamma\left(k^{*}\right)} .
$$

Note, that the Inada conditions guarantee that the RHS of equation (38) increases in the innovation market tightness $\varphi$ at a decreasing rate. Since in addition the RHS at $\varphi=0$ exceeds the LHS, i.e., $\operatorname{RHS}(0)>0$, equation (38) determines the unique innovation market tightness $\varphi$ for given innovation cost thresholds $k^{*}$ and $k^{* *}$. 


\subsubsection{Worker Flows and Labor Market Tightness}

We denote the measure of unemployed workers by $u$. Unemployment evolves according to the difference between inflows and outflows, i.e.,

$$
\dot{u}=\left\{\begin{array}{l}
\theta \lambda_{m}(\theta) u-\lambda_{d}\left(m^{B}\left(0, N_{i}^{B}\right) N_{i}^{B}+m^{R}\left(0, N_{i}^{R}\right) N_{i}^{R}\right) \text { if } L_{i}^{t}=0, \\
\theta \lambda_{m}(\theta) u-\delta\left(m^{B}\left(y, N_{i}^{B}\right) N_{i}^{B}+m^{R}\left(y, N_{i}^{R}\right) N_{i}^{R}\right) \text { if } L_{i}^{t}=N_{i}^{t} .
\end{array}\right.
$$

If all firms retain their workers if they are hit by a productivity shock, the inflow into unemployment is given by the rate $\lambda_{d}$ at which firms producing consumption goods with $y_{i}=0$ are destroyed times the number of workers that are employed at these firms, i.e., $m^{B}\left(0, N_{i}^{B}\right) N_{i}^{B}+m^{R}\left(0, N_{i}^{R}\right) N_{i}^{R}$. If all firms lay off their workers if they are hit by a productivity shock, the inflow into unemployment is given by the rate $\delta$ at which a productivity shock hits times the number of workers employed at firms producing consumption goods with $y_{i}=y$, i.e., $m^{B}\left(y, N_{i}^{B}\right) N_{i}^{B}+m^{R}\left(y, N_{i}^{R}\right) N_{i}^{R}$.

In Appendix A.6 we use the firm-level flow equations (32) to (37) to write employment under the different scenarios as a function of $m$, the number of firms in the economy. This allows us to write the labor market tightness $\theta$ as a function of the number of workers employed at type $B$ and $R$ firms, i.e., $N_{i}^{B}$ and $N_{i}^{R}$, as well as of the variables $\left\{\varphi, k^{*}, k^{* *}, m\right\}$, i.e.,

$$
\begin{aligned}
& \left(\frac{1}{\varphi}+\frac{\delta+\varphi g(\varphi)}{\left(\lambda_{s}+\eta\right) \varphi}+\frac{\delta+\lambda_{d}+g(\varphi)}{\delta}+\frac{\delta+\lambda_{d}+\eta}{\delta} \frac{\Gamma\left(k^{* *}\right)-\Gamma\left(k^{*}\right)}{1-\Gamma\left(k^{* *}\right)}\right) \frac{1}{m} \\
& =\left\{\begin{array}{l}
\left(\frac{\lambda_{d}}{\delta} \frac{\delta+\theta \lambda_{m}(\theta)}{\theta \lambda_{m}(\theta)}+\frac{\delta+g(\varphi)}{\delta}\right) N_{i}^{B} \\
+\left(\frac{\lambda_{d}}{\delta} \frac{\delta+\theta \lambda_{m}(\theta)}{\theta \lambda_{m}(\theta)}+\frac{\delta+\eta}{\delta}\right) \frac{\Gamma\left(k^{* *}\right)-\Gamma\left(k^{*}\right)}{1-\Gamma\left(k^{* *}\right)} N_{i}^{R} \text { if } L_{i}^{t}=0, \\
\frac{\delta+\theta \lambda_{m}(\theta)}{\theta \lambda_{m}(\theta)}\left(\frac{\lambda_{d}+g(\varphi)}{\delta} N_{i}^{B}+\frac{\Gamma\left(k^{* *}\right)-\Gamma\left(k^{*}\right)}{1-\Gamma\left(k^{* *}\right)} \frac{\lambda_{d}+\eta}{\delta} N_{i}^{R}\right) \text { if } L_{i}^{t}=N_{i}^{t},
\end{array}\right.
\end{aligned}
$$

where we differentiate between the two cases where all firms retain their workers and all firms lay off their workers if a productivity shock. The cases where either only type $B$ or only type $R$ firms lay off workers are described in Appendix A.6. 


\subsection{Equilibrium}

An equilibrium is characterized by the market tightness in the innovation and the labor markets, the layoff decision of type $B$ and $R$ firms $L_{i}^{B}$ and $L_{i}^{R}$, the threshold values $k^{*}$ and $k^{* *}$ of the innovation cost $k_{i}$ that determine the fraction of type $S, B$, and $R$ firms and the number of active firms in the economy $m$, i.e., by the set of variables $\left\{\varphi, \theta, L_{i}^{B}, L_{i}^{R}, k^{*}, k^{* *}, m\right\}$.

The innovation market tightness $\varphi$ is determined by equation (38). Comparative statics using the implicit function theorem imply that innovation market tightness $\varphi$ decreases with both innovation cost thresholds $k^{*}$ and $k^{* *}$, since, in the case of $k^{*}$, more

firms decide to specialize in innovation and, in case of $k^{* *}$, fewer firms decide to buy a new innovation when they are hit by a productivity shock.

The layoff decision for firm types $B$ and $R$ are given by substituting the respective values of an additional worker into the firing condition (19). Workers are laid off, i.e., $L_{i}^{t}=N_{i}^{t}$, if the marginal value of continuing an employment relationship plus the firing cost is negative, i.e., if and only if,

$$
\begin{gathered}
\frac{g(\varphi)(1-\beta)\left(\frac{c}{\lambda_{m}(\theta)}-\gamma f\right)-w^{I, B}\left(0, N_{i}^{B}\right)}{\left(r+\lambda_{d}+g(\varphi)(1-\beta)\right)}+f<0, \\
\quad \frac{\eta\left(\frac{c}{\lambda_{m}(\theta)}-\gamma f\right)-w^{I, R}\left(0, N_{i}^{R}\right)}{\left(r+\lambda_{d}+\eta\right)}+f<0,
\end{gathered}
$$

Bargaining wages are given in equations (20) to (25) for workers at firms with $y_{i} \in$ $\{0, y\}$ for the situation where all firms retain their workers if a productivity shock hits, and in equation (26) for the situation where workers are laid off once a productivity shock hits. The vacancy creation conditions for type $R$ and $B$ firms that do not lay off workers when they are hit by a productivity shock, i.e., if $L_{i}^{t}=0$, are given by substituting the respective values of an additional worker $\partial \pi^{O, t}\left(N_{i}^{t}, y, k_{i}\right) / \partial N_{i}^{t}$ at firms without workers 
into the general vacancy creation condition (16), i.e.,

$$
\frac{c}{\lambda_{m}(\theta)}=\left\{\begin{array}{l}
\frac{\left(r+\lambda_{d}+\eta\right)}{(r+\delta)\left(r+\lambda_{d}\right)+r \eta} \frac{(1-\gamma) \alpha}{1-\gamma(1-\alpha)} y\left(N_{i}^{R}\right)^{\alpha-1} \\
-\frac{\left(r+\delta+\lambda_{d}+\eta\right)((1-\gamma) z+\gamma \theta c)}{(r+\delta)\left(r+\lambda_{d}\right)+r \eta}, \text { for } t=R, \\
\frac{C_{2} \frac{(1-\gamma) \alpha}{C_{1}} y\left(N_{i}^{B}\right)^{\alpha-1}+\frac{\delta g(\varphi) \beta(1-\gamma)}{C_{1}} \beta g(\varphi) \gamma}{C_{1}}(1-\gamma) f \\
-\frac{C_{2}+\left(r+\lambda_{d}+g(\varphi)-\gamma \beta g(\varphi)\right) \delta}{C_{1}}((1-\gamma) z+\gamma \theta c), \text { for } t=B,
\end{array}\right.
$$

where

$$
\begin{aligned}
& C_{1}=C_{2}(r+\delta)-\left(r+\lambda_{d}+g(\varphi)-\gamma \beta g(\varphi)\right) \delta(1-(1-\gamma) \beta) g(\varphi), \\
& C_{2}=\left(r+\lambda_{d}+g(\varphi)\right)\left(r+\lambda_{d}+g(\varphi)(1-\beta)\right)
\end{aligned}
$$

The vacancy creation condition for the situation when firms lay off their workforce, i.e., if $L_{i}^{t}=N_{i}^{t}$, once they are hit by a productivity shock is given by,

$$
\frac{c}{\lambda_{m}(\theta)}=\frac{\frac{(1-\gamma) \alpha}{1-\gamma+\gamma \alpha} y\left(N_{i}^{t}\right)^{\alpha-1}-(1-\gamma) z-\gamma \theta c-(1-\gamma) \delta f}{r+\delta}
$$

All vacancy creation curves define the number of employed workers as a decreasing function of labor market tightness, i.e., $N_{i}^{t}(\theta)$ with $\partial N_{i}^{t}(\theta) / \partial \theta<0$. Substituting the respective functions $N_{i}^{t}(\theta)$ into the steady-state equation (40) determines labor market tightness as a function of $\left\{\varphi, L_{i}^{B}, L_{i}^{R}, k^{*}, k^{* *}, m\right\}$. The property $\partial N_{i}^{t}(\theta) / \partial \theta<0$ together with $\partial \theta\left(N_{i}^{R}, N_{i}^{B}\right) / \partial N_{i}^{t}>0$, guarantees that the equilibrium market tightness is unique for a given set of variables $\left\{\varphi, L_{i}^{B}, L_{i}^{R}, k^{*}, k^{* *}, m\right\}$. The comparative static result that a higher number of firms $m$ leads to higher labor market tightness $\theta$ ensures that the free entry condition (31) is well defined.

The innovation cost thresholds $k^{*}$ and $k^{* *}$ are determined by comparing the expected profits of the different types of firms as defined in equations (29) and (30). The single crossing property of the expected profits guarantees a unique pair of innovation cost thresholds $k^{*}$ and $k^{* *}$ for a given set of variables $\{\varphi, \theta, m\}$. Thus, firms with low innovation 
costs specialize in innovation, firms with high innovation costs buy innovations when they are hit by a productivity shock and firms with medium innovation costs do own research if they are hit by a productivity shock.

The final equation that determines the number of firms $m$ in equilibrium is the free entry condition (31), where the number of firms enters indirectly via the labor market tightness $\theta$. A higher number of firms $m$ increases, ceteris paribus, the labor market tightness $\theta$. A higher labor market tightness increases the recruitment cost of workers and thus decreases the expected profit of type $B$ and $R$ firms. Thus, the free entry condition is decreasing in the number of firms.

\section{Calibration}

In this section we show that our model is able to reconcile the empirical findings that the introduction of wrongful dismissal laws in the US lead to a decrease in productivity as shown by Autor, Kerr, and Kugler (2007) and an increase in the number of active firms and the number of patents as shown by Acharya, Baghai, and Subramanian (2014). We start with deriving the main measures that we need in order to compare our calibration results with the empiricial findings of Autor, Kerr, and Kugler (2007) and Acharya, Baghai, and Subramanian (2014).

\subsection{Definitions}

The number of patents and patent citations in our framework is measured by the number of innovations created each period, i.e.,

$$
I=m^{e}+\eta\left(m^{R}\left(0, N_{i}^{R}\right)+m^{S}(0,0)\right)
$$

In our model, there are two ways in which new innovations are created. All firms that enter the economy, i.e., $m^{e}$, are assumed to start with an innovation. Additionally, research is done by all type $S$ and type $R$ firms with $y_{i}=0$. These firms produce a new innovation at the research success rate $\eta$. 
Final output of consumption goods is given by all type $R$ and type $B$ firms with productivity $y_{i}=y$, i.e.,

$$
Y=m^{R}\left(y, N_{i}^{R}\right) y\left(N_{i}^{R}\right)^{\alpha}+m^{B}\left(y, N_{i}^{B}\right) y\left(N_{i}^{B}\right)^{\alpha}
$$

The number of employed workers is given by taking the sum over all workers employed by type $R$ and type $B$ firms, i.e.,

$$
l=\left\{\begin{array}{l}
\left(m^{R}\left(y, N_{i}^{R}\right)+m^{R}\left(0, N_{i}^{R}\right)\right) N_{i}^{R}+\left(m^{B}\left(y, N_{i}^{B}\right)+m^{B}\left(0, N_{i}^{B}\right)\right) N_{i}^{B} \text { if } L_{i}^{t}=0 \\
m^{R}\left(y, N_{i}^{R}\right) N_{i}^{R}+m^{B}\left(y, N_{i}^{B}\right) N_{i}^{B} \text { if } L_{i}^{t}=N_{i}^{t} .
\end{array}\right.
$$

\subsection{Baseline calibration}

\subsubsection{Parameters and targets}

The model comprises of 17 exogenous parameters (see Table 1). In the calibration we choose the time period to represent one quarter and set the quarterly discount rate to $r=0.012$ (equivalent to an annual discount factor of 0.953 ).

The parameters to target aggregate labor market statistics are taken from Shimer (2005) and Kaas and Kircher (2011) among others. We use a standard Cobb-Douglas type matching function, i.e., $M(U, V)=\kappa_{l} U^{\psi} V^{1-\psi}$. Like Shimer (2005) we target a job finding rate $\theta \lambda_{m}(\theta)$ of 1.36 . Moreover, we target an unemployment rate in line with the long run US average (4.5\% to $5 \%$ ). To do so we set the labor market matching efficiency parameter to $\kappa_{l}=2$ and the vacancy posting costs to $c=0.0352$. The matching elasticity on the labor market $\psi$ is set at a medium value of 0.5 . As workers in our model are all production workers unemployment benefits are set at a fairly high value $z=0.575$, implying a replacement rate of $85 \%$, which is close to ?. Finally, workers' bargaining power $\gamma$ is set at 0.72 (see Shimer (2005)). To specify the parameters of the production function for large firms we follow Kaas and Kircher (2011). We normalize the productivity parameter to $y=1$ and set the labor elasticity parameter of the production function $\alpha$ equal to the labor share of 0.7. Bauer and Lingens (2013), who also calibrate a matching model with large firms, take a value of 0.8 for the labor elasticity parameter. They 
motivate their choice by targeting realistic mark-up values. Taking a value of 0.8 instead of 0.7 for labor elasticity would change our results quantitatively but not qualitatively.

We assume that research costs are uniformly distributed between zero and one. The support of the research cost distribution is chosen such that the threshold values for the investment cost can be directly used to obtain the shares of the respective firm types. Using the uniform distribution on the $[0,1]$ support implies a R\&D expenditure to GDP ratio of around 0.014, a value that is of the same magnitude as the $2 \%$ of GDP reported in Eurostat (2011) for private sector R\&D expenditure in the US. The productivity shock rate $\delta$ is calibrated in order to reflect average product life-cycle length. Magnier, Kalaitzandonakes, and Miller (2010) find that on average products last for about 2.5 years, implying $\delta=0.1$. In order to obtain a value for the research success rate $\eta$ we use a result by Griffin (2002), who finds that the ratio of product life cycle length to the time to market for the development of a new product is 3.56 in almost all industries (i.e., the product life cycle length and the time to market are extremely highly correlated across industries with $\rho=0.99$ ). Given the ratio of product life cycle length to the time to market of 3.56 we set the research success rate at $\eta=0.356$.

There is less information in the literature that we can use in order to pin down the parameters for the innovation market. We also use a Cobb-Douglas type matching functions for the innovation market, i.e., $P(S, B)=\kappa_{p}(S)^{\nu} B^{1-\nu}$. We set the exponent of the innovation market matching function to $\nu=0.5$ in order to derive an explicit expression for the innovation market tightness, which is done to reduce the computer capacity necessary to solve the model numerically. The bargaining power of firms that sell their product ideas in the innovation market is also chosen to equal $\beta=0.5$. We choose a matching efficiency in the innovation market of $\kappa_{p}=0.18$ in order to obtain an innovation acquisition rate $g(\varphi)$ that is of roughly the same magnitude as the research success rate $\eta$ for firms that do their own research.

Firing costs $f=1$ are chosen to equal 4.5 month of production in the calibration with employment protection and zero otherwise. Given the fact that only 13 US states have adopted the "good-faith" exception, the value $f=1$ seem appropriate since it imples 
roughly an average value of one month of production for the US as a whole.

Table 1 - Exogenous parameters values

\begin{tabular}{|c|c|c|}
\hline Parameter & Value & Source / Target \\
\hline$\delta$ & 0.100 & $\begin{array}{l}\text { Target: Average product cycle length, see Magnier, Kalaitzandonakes, and } \\
\text { Miller (2010). }\end{array}$ \\
\hline$\lambda_{d}$ & 0.250 & Target: Average firm life expectancy of 50 quarters, see Burns (2010). \\
\hline$\lambda_{s}$ & 0.010 & Set to equal $25 \lambda_{d}=\lambda_{s}$. \\
\hline$\eta$ & 0.356 & $\begin{array}{l}\text { Set to equal the ratio of average product life cycle length to time to market } \\
\text { of } 3.56 \text {, see Griffin (2002). }\end{array}$ \\
\hline$y$ & 1.000 & Normalisation. \\
\hline$\alpha$ & 0.700 & Set to equal the labor share, see Kaas and Kircher (2011). \\
\hline$\psi$ & 0.500 & Set to the medium value, see Mortensen and Pissarides (1994). \\
\hline$\kappa_{l}$ & 2.000 & $\begin{array}{l}\text { Target: Average job-finding rate of } 1.36 \text { (Shimer (2005)) and unemployment } \\
\text { rate of about } 5 \% \text {. }\end{array}$ \\
\hline$\nu$ & 0.500 & Set due to computational constraints. \\
\hline$\kappa_{p}$ & 0.180 & Set to get a product idea finding rate of $g(\varphi)=\eta$. \\
\hline$\gamma$ & 0.720 & See to an conventional value Shimer (2005). \\
\hline$\beta$ & 0.500 & Set to equal the elasticity of the innovation market matching function. \\
\hline$z$ & 0.575 & Target: Replacement rate of $85 \%$. \\
\hline$c$ & 0.035 & $\begin{array}{l}\text { Target: Average job-finding rate of } 1.36 \text { (Shimer (2005)) and unemployment } \\
\text { rate of about } 5 \% \text {. }\end{array}$ \\
\hline$r$ & 0.012 & Compare Shimer (2005). \\
\hline$f$ & 1.000 & $\begin{array}{l}\text { Set to equal } 4.5 \text { months of wages, see Bartelsman, Gautier, and De Wind } \\
(2010) \text {. }\end{array}$ \\
\hline$F$ & 2.88 & $\begin{array}{l}\text { Set to get an average of } 2.58 \text { production workers per establishment(see U.S. } \\
\text { Census }(2007)) \text {. }\end{array}$ \\
\hline
\end{tabular}

The firm level destruction rates $\lambda_{d}$ and $\lambda_{s}$ are chosen such that the average life expectancy of firms lies somewhere around 50 quarters (see Burns (2010)). We set the destruction shock of producing firms to be much larger than the destruction shock of firms that specialize in innovation, i.e., $\lambda_{d}=0.25$ and $\lambda_{s}=0.01$, since type $S$ firms are more often exposed to the " $y_{i}=0$ "-state then type $R$ and type $B$ firms given that $y_{i}=0$ every time they sell their innovation.

Finally we set entry costs to $F=2.88$, which leads to firm-level employment of 2.58 production workers at type $R$ and type $B$ firms. Since we do not include non-production workers we have chosen a value that is significantly smaller than the average US firm size 
of around 4.18 employees (production and non-production workers) documented by U.S. Census (2007).

\subsubsection{Baseline calibration of the US economy}

The first column of Table 2 below shows the baseline calibration of the US economy without employment protection. Given the normalization of the number of workers in the economy and the productivity parameter to one, final consumption output without employment protection is equal to 0.717 . The total measure of innovations per quarter of 0.048 consist of the innovations done by existing firms 0.032 (innovations within), and firms, which enter the economy 0.016 (innovations upon entry). The private sector R\&D expenditure to GDP ratio equals 0.014. Firms that acquire an innovation are willing to pay on average 1.027. The rate at which type $B$ firms are able to acquire a new machinery or product idea $y$ in the market for innovations equals 0.307. Taking the weighted average over type $B$ and type $R$ firms then the average duration in which a firm is in the low productivity state $y_{i}=0$ is slightly more than 9.2 months.

In steady state the free entry condition ensures that average expected profits exactly offset entry costs $F$. This pins down the number of firms in the economy at $m=0.614$, out of which 0.369 produce the final consumption goods. The remaining firms either conduct own research 0.089 or search for a trading partner in the innovation market 0.155 . The unemployment rate among production workers is given by 0.048 .

\subsection{Introducing employment protection}

In order to shed light on the interaction of employment protection and innovations we first keep the innovation price fixed at the level without employment protection. Later, we endogenize the price to demonstrate the role of the innovation market.

\subsubsection{Fixed innovation price}

Table 2 compares the baseline model without employment protection with a situation in which employment protection is in place. However, the average innovation price is kept 
constant at 1.027, the level in the baseline calibration. In order to understand the effect on profits, we first kept the number of firms in the economy constant at 0.614. This is shown in the second column of Table 2 .

Table 2 - Results: Employment protection with fixed idea price

\begin{tabular}{lccc} 
Variable & $\begin{array}{c}\text { Baseline } \\
\text { without EPL }\end{array}$ & $\begin{array}{c}\text { With EPL } \\
\text { m-fixed }\end{array}$ & $\begin{array}{c}\text { With EPL } \\
\text { m-flexible }\end{array}$ \\
\hline Final consumption output $(\mathrm{Y})$ & 0.717 & 0.637 & 0.604 \\
Total innovations $(\mathrm{I})$ & 0.048 & 0.048 & 0.043 \\
Total R\&D costs / GDP & 0.014 & 0.014 & 0.014 \\
\hline Seller-researcher threshold $\left(k^{*}\right)$ & 0.039 & 0.043 & 0.040 \\
Researcher-buyer threshold $\left(k^{* *}\right)$ & 0.402 & 0.366 & 0.388 \\
\hline Innovation acquisition rate $(g(\varphi))$ & 0.307 & 0.315 & 0.307 \\
Innovation price $(p)$ & 1.027 & 1.027 & 1.027 \\
\hline Unemployment rate $(u)$ & 0.048 & 0.043 & 0.075 \\
Job finding rate $(\theta g(\theta))$ & 1.998 & 0.822 & 0.456 \\
Job destruction rate & 0.100 & 0.037 & 0.037 \\
Firm-level employment & & & 2.550 \\
$\quad$ Type R firms $\left(N_{i}^{R}\right)$ & 2.581 & 2.394 & 2.350 \\
$\quad$ Type B firms $\left(N_{i}^{B}\right)$ & 2.581 & 2.221 & 0.545 \\
\hline Total number of firms $(m)$ & 0.614 & 0.614 & 0.105 \\
$\quad$ Type S with $y_{i}=y$ & 0.115 & 0.125 & 0.059 \\
$\quad$ Type S with $y_{i}=0$ & 0.065 & 0.069 & 0.124 \\
Type R with $y_{i}=y$ & 0.147 & 0.126 & 0.021 \\
$\quad$ Type R with $y_{i}=0$ & 0.024 & 0.021 & 0.200 \\
$\quad$ Type B with $y_{i}=y$ & 0.222 & 0.231 & 0.036 \\
$\quad$ Type B with $y_{i}=0$ & 0.040 & 0.041 & 0.027 \\
$\quad$ Firms with employment & 0.369 & 0.026 & \\
Average firm destruction rate & 0.027 & 2.758 & \\
\hline Average profit & 2.882 & & \\
\hline
\end{tabular}

The introduction of employment protection implies that firms continue to employ their workers, if they are hit by a productivity shock. This increases the number of firms with employment by $14 \%$. Although there are more firms, which employ workers, the number of firms producing the final consumption good decreases, because keeping and paying unproductive workers decreases profits, especially profits of type $R$ and type $B$ firms, and 
makes it more attractive to specialize in innovation. Higher labor costs also imply that firm-level employment drops on average by $10.5 \%$. Both negative effects lead to a drop in final consumption output.

Unemployment falls (slightly) as job destruction decreases even more than job creation. The effect on job destruction emerges because under employment protection not only those type $R$ and type $B$ firms, which have not been hit by a productivity shock, but all type $R$ and type $B$ firms employ workers. The drop in the unemployment rate shown in the second column does not yet take the negative effect of employment protection on firm entry and the respective (additional) negative effect on vacancy creation into account.

The adoption of employment protection laws decreases average profits by roughly $4.4 \%$ implying that the total number of firms in the economy with employment protection decreases by about $11.3 \%$. This can be seen by looking at the third column of Table 2 , which keeps the innovation prices constant, but allows for adjustment of the number of firms. The number of innovations also decreases with the number of firms by about $10 \%$. Unemployment significantly increases (from $4.8 \%$ to $7.5 \%$ ) once the additional effect of lower firm entry is taken into account.

Thus, without the innovation market channel (flexible innovation price) our model is not able to replicate the empirical findings by Acharya, Baghai, and Subramanian (2014) , who find a positive effect of employment protection on the number of patents and an increase in the number of firms. In addtion, the model is at odds with the empirical evidence showing that employment protection has only mild effects on unemployment.

\subsubsection{Endogenous innovation price}

Until now we fixed the innovation price at its baseline value in order to disentangle the innovation market effect from the conventional profit depressing effects of employment protection. We now compare the baseline calibration with the model with employment protection under flexible innovation prices. Again, the second column of Table 3 keeps the number of firms in the economy at the baseline calibration level in order to understand the effects of employment protection on profits. 
The introduction of employment protection increases labor cost during the period in which a firm keeps its workers although it has been hit by a productivity shock. This increases the willingness of firms, which have been hit by a productivity shock, to pay for an innovation. This leads to an increase in the innovation price from 1.027 in the baseline calibration to 1.365. This increases the profits of firms that specialize in innovation relative to the profit of final consumption good producers. The associated shift in the composition of firms increases the number of innovations by type $S$ and type $R$ firms, by around $10 \%$. The total number of innovations does not change, however, since we keep the number of firms fixed, which implies that we exclude all innovations that are attached to the entry of new firms. ${ }^{3}$

The change in the composition of firms mainly increases the number of type $S$ firms that spezialize in innovation and decreases the number of type $R$ and type $B$ firms that produce consumption goods from 0.369 to 0.312 . Although the reduction in the number of producing firms leads to lower hiring costs and higher profits, firm-level employment sligtly decreases as firing costs effectively increase the marginal costs of employing a worker. Accordingly unemployment strongly increases (from 0,048\% to $0.079 \%$ ) whereas final consumption output decreases by around $16.2 \%$.

In stark contrast to the calibration in Table 2 with fixed product idea prices, average profits increase by around 4\%. This triggers firm entry and increases in the number of firms in the new steady state from 0.614 to 0.670 . The increase in the number of firms of around $9.1 \%$ is well in line with the $8.7 \%$ to $12.4 \%$ increase estimated by Acharya, Baghai, and Subramanian (2014).

The increase in the total number of firms has a counteracting effect on the average innovation price, which decreases from 1.365 in the calibration with the fixed number of firms to 1.323. However, the above mentioned shift in the composition of firms towards a higher fraction of firms that specialize in innovation is still present and leads in combination with the innovations generated by newly created firms to an increase in total innovations of around $8.3 \%$. This increase is slightly below the one estimated by

\footnotetext{
${ }^{3}$ As $\lambda_{s} \leq \lambda_{d}$ the change in the composition of firms towards more sellers leads to less exits per period and accordingly to less entries per period.
} 
Table 3 - Results: Employment protection with endogenous idea price

\begin{tabular}{lccc} 
Variable & $\begin{array}{c}\text { Baseline } \\
\text { without EPL }\end{array}$ & $\begin{array}{c}\text { With EPL } \\
\text { m-fixed }\end{array}$ & $\begin{array}{c}\text { With EPL } \\
\text { m-flexible }\end{array}$ \\
\hline Final consumption output $(\mathrm{Y})$ & 0.717 & 0.601 & 0.632 \\
Total innovations $(\mathrm{I})$ & 0.048 & 0.048 & 0.053 \\
Total R\&D costs / GDP & 0.014 & 0.013 & 0.013 \\
\hline Seller-researcher threshold $\left(k^{*}\right)$ & 0.039 & 0.064 & 0.064 \\
Researcher-buyer threshold $\left(k^{* *}\right)$ & 0.402 & 0.344 & 0.337 \\
\hline Innovation acquisition rate $(g(\varphi))$ & 0.307 & 0.400 & 0.397 \\
Innovation price $(p)$ & 1.027 & 1.365 & 1.323 \\
\hline Unemployment rate $(u)$ & 0.048 & 0.079 & 0.045 \\
Job finding rate $(\theta g(\theta))$ & 1.998 & 0.396 & 0.722 \\
Job destruction rate & 0.100 & 0.034 & 0.034 \\
Firm-level employment & & & \\
$\quad$ Type R firms $\left(N_{i}^{R}\right)$ & 2.581 & 2.568 & 2.444 \\
$\quad$ Type B firms $\left(N_{i}^{B}\right)$ & 2.581 & 2.544 & 2.416 \\
\hline Total number of firms $(m)$ & 0.614 & 0.614 & 0.670 \\
$\quad$ Type S with $y_{i}=y$ & 0.115 & 0.169 & 0.185 \\
Type S with $y_{i}=0$ & 0.065 & 0.084 & 0.092 \\
Type R with $y_{i}=y$ & 0.147 & 0.088 & 0.095 \\
Type R with $y_{i}=0$ & 0.024 & 0.015 & 0.016 \\
Type B with $y_{i}=y$ & 0.222 & 0.223 & 0.246 \\
Type B with $y_{i}=0$ & 0.040 & 0.034 & 0.038 \\
$\quad$ Firms with employment & 0.369 & 0.361 & \\
Average firm destruction rate & 0.027 & 0.021 & \\
\hline Average profit & 2.882 & & 0.996 \\
\hline
\end{tabular}

Acharya, Baghai, and Subramanian (2014), which lies between $12.2 \%$ and $18.8 \%$. This shift in economic activity towards firms that specialize in innovation also increases the innovation acquisition rate $g(\varphi)$ at which type $B$ firms can restore their productivity from 0.307 in the baseline calibration to 0.397 . Taking the weighted average over type $B$ and type $R$ firms then the average duration in which a firm is in the low productivity state $y_{i}=0$ is with employment protection equal to 7.8 months. This implies a decrease of $15.7 \%$ compared to the average duration without employment protection of 9.2 months.

The higher number of firms $m$ and the higher innovation acquisition rate dampen the 
decrease in the number of firms producing consumption goods. Nevertheless it is still lower than in the calibration without employment protection (0.340 instead of 0.369 ). Together with the decrease in firm-level employment of around $6 \%$ on average, this still leads to a substantial decline in the production of final consumption goods by $11.8 \%$. In contrast to final consumption output, unemployment fully recovers from its high value in the calibration with fixed firm numbers once the increase in $m$ is taken into account. Indeed, as unemployment falls to $4.5 \%$ it is even slightly below its original value, which was $4.8 \%$. The model is therefore well in line with the empirical fact that employment protection can have ambiguous effects on unemployment. Since the decrease in final consumption output goes along with an increase in total employment, an increase in the number of firms, and an increase in the number of innovations our calibration is also able to explain the decrease in labor and total factor productivity due to employment protection observed by Autor, Kerr, and Kugler (2007).

\section{Conclusion}

We study the effects of employment protection taking into account that firms are able to restore their productivity. We develop an equilibrium matching model with an imperfect labor and innovation market. We model both markets as matching markets, where the time to find an appropriate trading partner depends on the ratio of buyers to sellers in the market, and where prices are negotiated bilaterally. The interaction between labor and innovation market has the following implication. Employment protection induces firms to keep workers employed even if productivity has dropped. This increases firms' willingness to pay for product or process innovations in order to restore productivity. This increases the price for innovations, triggers entry of new start-ups and shifts economic activity towards firms specializing in process and product innovation. It hence increases the rate at which firms that are hit by a negative productivity shock can purchase the (process or product) innovation necessary to restore their productivity.

We calibrate our model to match aggregate US labor and product market statistics as well as aggregate firm exit and entry rates. We then take the calibrated model, introduce 
employment protection and show that the rate at which firms are able to restore their productivity increases. Our comparative static results are also in line with the estimated negative impact of wrongful dismissal laws on productivity, the positive effect on innovations and the number of firms, especially start-ups. We also find evidence for a shift in economic activity towards firms specializing in producing machinery (process innovation) or product ideas (product innovation).

\section{References}

Acharya, V. V., R. P. Baghai, and K. V. Subramanian (2014): "Wrongful Discharge Laws and Innovation," Review of Financial Studies, 27(1), 301-346.

Akerlof, G. A. (1984): An Economist's Book of Tales. Cambridge University Press.

Autor, D., J. Donohue, and S. Schwab (2006): "The Costs of Wrongful-Discharge Laws," The Review of Economics and Statistics, 88(2), 211-231.

Autor, D., W. Kerr, and A. Kugler (2007): "Does Employment Protection Reduce Productivity? Evidence from US States," The Economic Journal, 117, 189-217.

Baldwin, J., And W. Gu (2006): "Plant Turnover and Productivity Growth in Canadian Manufacturing," Industrial and Corporate Change, 15(3), 417-465.

Bartelsman, E., P. Gautier, and J. De Wind (2010): "Employment Protection, Technology Choice, and Worker Allocation," IZA Discussion Papers 4895, Institute for the Study of Labor (IZA).

Bartelsman, E., J. Haltiwanger, and S. Scarpetta (2009): "Measuring and Analyzing Cross-Country Differences in Firm Dynamics," in Producer Dynamics: New Evidence from Micro Data, NBER Chapters, pp. 15-76. National Bureau of Economic Research, Inc.

Bauer, C., And J. Lingens (2013): "Does Collective Wage Bargaining Restore Efficiency in a Search Model with Large Firms?," The Economic Journal, forthcoming. 
Belot, M., J. Boone, and J. V. Ours (2007): "Welfare-Improving Employment Protection," Economica, 74(295), 381-396.

Burns, P. (2010): Entrepreneurship and Small Business. Palgrave Macmillan, 3rd edn.

Cahuc, C., F. Marque, and E. Wasmer (2008): "A Theory Of Wages And Labor Demand With Intra-Firm Bargaining And Matching Frictions," International Economic Review, 49(3), 943-972.

Cahuc, P., And E. Wasmer (2001): "Does Intrafirm Bargaining Matter in the Large Firm's Matching Model," Macroeconomic Dynamics, 5(5), 742-747.

Disney, R., J. Haskel, and Y. Heden (2003): "Restructuring and Productivity Growth in UK Manufacturing," Economic Journal, 113(489), 666-694.

Eurostat (2011): "Research and Development Expenditures by Sectors of Performance," http://epp.eurostat.ec.europa.eu/.

Foster, L., J. C. Haltiwanger, and C. J. Krizan (2001): "Aggregate Productivity Growth. Lessons from Microeconomic Evidence," in New Developments in Productivity Analysis, NBER Chapters, pp. 303-372. National Bureau of Economic Research, Inc.

Griffin, A. (2002): "Product Development Cycle Time for Business-to-Business Products," Industrial Marketing Management, 31, 291-304.

Griliches, Z., and H. Regev (1995): "Firm Productivity in Israeli Industry 19791988," Journal of Econometrics, 65(1), 175-203.

Hopenhayn, H., and R. Rogerson (1993): "Job Turnover and Policy Evaluation: A General Equilibrium Analysis," Journal of Political Economy, 101(5), 915-938.

KaAs, L., And P. Kircher (2011): "Efficient Firm Dynamics in a Frictional Labor Market," IZA Discussion Papers 5452, Institute for the Study of Labor (IZA). 
Magnier, A., N. Kalaitzandonakes, and D. Miller (2010): "Product Life Cycles and Innovation in the US Sees Corn Industry," International Food and Agribusiness Management Review, 13(3), 17-36.

Mortensen, D., And C. Pissarides (1994): "Job Creation and Job Ddestruction in the Theory of Unemployment," Review of Economic Studies, 61(3), 397-415.

Olley, G. S., And A. Pakes (1996): "The Dynamics of Productivity in the Telecommunications Equipment Industry," Econometrica, 64(6), 1263-1297.

Pierre, G., and S. Scarpetta (2004): "Employment Regulations Through the Eyes of Employers: Do They Matter and How Do Firms Respond to Them?," IZA Discussion Papers 1424, Institute for the Study of Labor (IZA).

Shimer, R. (2005): "The Cyclical Behavior of Equilibrium Unemployment and Vacancies," American Economic Review, 95(1), 25 - 49.

Smith, E. (1999): "Search, Concave Production, and Optimal Firm Size," Review of Economic Dynamics, 2(2), 456-471.

Soskice, D. (1997): “German Technology Policy, Innovation and National Institutional Frameworks," Industry and Innovation, pp. 75-96.

U.S. CEnsus (2007): "Statistics about Business Size," http://www.census.gov/econ/smallbus.html.

WAsmer, E. (2006): "Interpreting Europe and US Labor Markets Differences : The Specificity of Human Capital Investments," American Economic Review, 96(3), 811831.

Zoega, G., And A. Booth (2003): "On the Welfare Implications of Firing Costs," European Journal of Political Economy, 19, 759-775. 


\section{Appendix}

\section{A Derivations in section 2}

\section{A.1 Wage equations}

Let us first consider the wages paid in type $R$ firms. Wage bargaining according to equations (14) and (15) implies the following surplus splitting rule for outsiders in firms with $y_{i}=y$, for insiders in firms with $y_{i}=y$ and for insiders in firms with $y_{i}=0$,

$$
\begin{aligned}
& (1-\gamma)\left(W^{O, R}\left(w^{O, R}\left(y, N_{i}^{R}\right)\right)-U\right)=\gamma\left(\frac{\partial \pi^{O, R}\left(N_{i}^{R}, y, k_{i}\right)}{\partial N_{i}^{R}}\right) \\
& (1-\gamma)\left(W^{I, R}\left(w^{I, R}\left(y, N_{i}^{R}\right)\right)-U\right)=\gamma\left(\frac{\partial \pi^{I, R}\left(N_{i}^{R}, y, k_{i}\right)}{\partial N_{i}^{R}}+f\right) \\
& (1-\gamma)\left(W^{I, R}\left(w^{I, R}\left(0, N_{i}^{R}\right)\right)-U\right)=\gamma\left(\frac{\partial \pi^{I, R}\left(N_{i}^{R}, 0, k_{i}\right)}{\partial N_{i}^{R}}+f\right)
\end{aligned}
$$

where firms only have to pay firing costs $f$, if they do not continue to employ an insider. Subsititung the marginal value of a worker in the respective situation from equations (17) and (18), i.e.,

$$
\begin{aligned}
\frac{\partial \pi^{O, R}\left(N_{i}^{R}, y, k_{i}\right)}{\partial N_{i}^{R}} & =\frac{\alpha y\left(N_{i}^{R}\right)^{\alpha-1}-w^{O, R}\left(y, N_{i}^{R}\right)-\frac{\partial w^{O, R}\left(y, N_{i}^{R}\right)}{\partial N_{i}^{R}} N_{i}^{R}+\delta \frac{\partial \pi^{I, R}\left(N_{i}^{R}, 0, k_{i}\right)}{\partial N_{i}^{R}}}{(r+\delta)}, \\
\frac{\partial \pi^{I, R}\left(N_{i}^{R}, y, k_{i}\right)}{\partial N_{i}^{R}} & =\frac{\alpha y\left(N_{i}^{R}\right)^{\alpha-1}-w^{I, R}\left(y, N_{i}^{R}\right)-\frac{\partial w^{I, R}\left(y, N_{i}^{R}\right)}{\partial N_{i}^{R}} N_{i}^{R}+\delta \frac{\partial \pi^{I, R}\left(N_{i}^{R}, 0, k_{i}\right)}{\partial N_{i}^{R}}}{(r+\delta)}, \\
\frac{\partial \pi^{I, R}\left(N_{i}^{R}, 0, k_{i}\right)}{\partial N_{i}^{R}} & =\frac{-w^{I, R}\left(0, N_{i}^{R}\right)-\frac{\partial w^{I, R}\left(0, N_{i}^{R}\right)}{\partial N_{i}^{R}} N_{i}^{R}+\eta \frac{\partial \pi^{I, R}\left(N_{i}^{R}, y, k_{i}\right)}{\partial N_{i}^{R}}}{\left(r+\lambda_{d}+\eta\right)},
\end{aligned}
$$

and the workers' surplus from employment using equations (2) and (4), i.e.,

$$
\begin{gathered}
{\left[W^{O, R}\left(w^{O, R}\left(y, N_{i}^{R}\right)\right)-U\right]=\frac{w^{O, R}\left(y, N_{i}^{R}\right)-r U+\delta\left[W^{I, R}\left(w^{R}\left(0, N_{i}\right)\right)-U\right]}{(r+\delta)},} \\
{\left[W^{I, R}\left(w^{I, R}\left(y, N_{i}^{R}\right)\right)-U\right]=\frac{w^{I, R}\left(y, N_{i}^{R}\right)-r U+\delta\left[W^{I, R}\left(w^{R}\left(0, N_{i}\right)\right)-U\right]}{(r+\delta)},} \\
{\left[W^{I, R}\left(w^{I, R}\left(0, N_{i}^{R}\right)\right)-U\right]=\frac{w^{I, R}\left(0, N_{i}\right)-r U+\eta\left[W^{I, R}\left(w^{i, R}\left(y, N_{i}\right)\right)-U\right]}{\left(r+\eta+\lambda_{d}\right)},}
\end{gathered}
$$


and rearranging using again the surplus splitting rules in the equations above, leads to the following differential wage equations,

$$
\begin{aligned}
w^{O, R}\left(y, N_{i}^{R}\right) & =(1-\gamma) r U+\gamma\left(\alpha y\left(N_{i}^{R}\right)^{\alpha-1}-\frac{\partial w^{O, R}\left(y, N_{i}^{R}\right)}{\partial N_{i}^{R}} N_{i}^{R}\right)-\gamma \delta f, \\
w^{I, R}\left(y, N_{i}^{R}\right) & =(1-\gamma) r U+\gamma\left(\alpha y\left(N_{i}^{R}\right)^{\alpha-1}-\frac{\partial w^{I, R}\left(y, N_{i}^{R}\right)}{\partial N_{i}^{R}} N_{i}^{R}\right)+\gamma r f, \\
w^{I, R}\left(0, N_{i}^{R}\right) & =(1-\gamma) r U-\gamma \frac{\partial w^{I, R}\left(0, N_{i}^{R}\right)}{\partial N_{i}^{R}} N_{i}^{R}+\gamma\left(r+\lambda_{d}\right) f,
\end{aligned}
$$

Solving the differential equations for $w^{O, R}\left(y, N_{i}^{R}\right)$ and $w^{I, R}\left(y, N_{i}^{R}\right)$ following Cahuc and Wasmer (2001) and Cahuc, Marque, and Wasmer (2008) gives the wage equations in section 2.4.3, where we substituted the value of being unemployed by $(1-\gamma) r U=$ $(1-\gamma) z+\gamma \theta c$. The differential wage equation for $w^{I, R}\left(0, N_{i}\right)$ is independent of $N_{i}^{R}$ and is therefore given by setting $\partial w^{I, R}\left(0, N_{i}^{R}\right) / \partial N_{i}^{R}=0$.

Now consider wages paid by type $B$ firms. The surplus splitting rules are given by,

$$
\begin{aligned}
(1-\gamma)\left(W^{O, B}\left(w^{O, B}\left(y, N_{i}^{B}\right)\right)-U\right) & =\gamma\left(\frac{\partial \pi^{O, B}\left(N_{i}^{B}, y, k_{i}\right)}{\partial N_{i}^{B}}\right) \\
(1-\gamma)\left(W^{I, B}\left(w^{I, B}\left(y, N_{i}^{B}\right)\right)-U\right) & =\gamma\left(\frac{\partial \pi^{I, B}\left(N_{i}^{B}, y, k_{i}\right)}{\partial N_{i}^{B}}+f\right) \\
(1-\gamma)\left(W^{I, B}\left(w^{I, B}\left(0, N_{i}^{B}\right)\right)-U\right) & =\gamma \frac{r+\lambda_{d}+g(\varphi)(1-\beta)}{r+\lambda_{d}+g(\varphi)}\left(\frac{\partial \pi^{I, B}\left(N_{i}^{B}, 0, k_{i}\right)}{\partial N_{i}^{B}}+f\right),
\end{aligned}
$$

where the surplus splitting rule for the case with $y_{i}=0$ takes into account that innovation price bargaining implies that part of the marginal value of continuing the employment relationship (the fraction $\beta$ ) is going to the seller. This causes the additional term in the last equation. The marginal values of employing a worker are given by,

$$
\begin{aligned}
\frac{\partial \pi^{O, B}\left(N_{i}^{B}, y, k_{i}\right)}{\partial N_{i}^{B}} & =\frac{\alpha y\left(N_{i}^{B}\right)^{\alpha-1}-w^{O, B}\left(y, N_{i}^{B}\right)-\frac{\partial w^{O, B}\left(y, N_{i}^{B}\right)}{\partial N_{i}^{B}} N_{i}^{B}+\delta \frac{\partial \pi^{I, B}\left(N_{i}^{B}, 0, k_{i}\right)}{\partial N_{i}^{B}}}{(r+\delta)}, \\
\frac{\partial \pi^{I, B}\left(N_{i}^{B}, y, k_{i}\right)}{\partial N_{i}^{B}} & =\frac{\alpha y\left(N_{i}^{B}\right)^{\alpha-1}-w^{I, B}\left(y, N_{i}^{B}\right)-\frac{\partial w^{I, B}\left(y, N_{i}^{B}\right)}{\partial N_{i}^{B}} N_{i}^{B}+\delta \frac{\partial \pi^{I, B}\left(N_{i}^{B}, 0, k_{i}\right)}{\partial N_{i}^{B}}}{(r+\delta)}, \\
\frac{\partial \pi^{I, B}\left(N_{i}^{B}, 0, k_{i}\right)}{\partial N_{i}^{B}} & =\frac{-w^{I, B}\left(0, N_{i}^{B}\right)-\frac{\partial w^{I, B}\left(0, N_{i}^{B}\right)}{\partial N_{i}^{B}} N_{i}^{B}+g(\varphi)(1-\beta) \frac{\partial \pi^{I, B}\left(N_{i}^{B}, y, k_{i}\right)}{\partial N_{i}^{B}}}{\left(r+\lambda_{d}+g(\varphi)(1-\beta)\right)},
\end{aligned}
$$


and the workers' surplus from employment by,

$$
\begin{gathered}
{\left[W^{O, B}\left(w^{O, B}\left(y, N_{i}^{B}\right)\right)-U\right]=\frac{w^{O, B}\left(y, N_{i}^{B}\right)-r U+\delta\left[W^{I, B}\left(w^{I, B}\left(0, N_{i}^{B}\right)\right)-U\right]}{(r+\delta)},} \\
{\left[W^{I, B}\left(w^{I, B}\left(y, N_{i}^{B}\right)\right)-U\right]=\frac{w^{I, B}\left(y, N_{i}^{B}\right)-r U+\delta\left[W^{I, B}\left(w^{I, B}\left(0, N_{i}^{B}\right)\right)-U\right]}{(r+\delta)},} \\
{\left[W^{I, B}\left(w^{I, B}\left(0, N_{i}^{B}\right)\right)-U\right]=\frac{w^{I, B}\left(0, N_{i}^{B}\right)-r U+g(\varphi)\left[W^{I, B}\left(w^{I, B}\left(y, N_{i}\right)\right)-U\right]}{\left(r+\lambda_{d}+g(\varphi)\right)} .}
\end{gathered}
$$

Substituting implies the following differential wage equations,

$$
\begin{aligned}
w^{O, B}\left(y, N_{i}^{B}\right) & =(1-\gamma) r U+\gamma \alpha y\left(N_{i}^{B}\right)^{\alpha-1}-\gamma \frac{\partial w^{O, B}\left(y, N_{i}^{B}\right)}{\partial N_{i}^{B}} N_{i}^{B}-\delta \gamma f \\
& +\delta \frac{\beta g(\varphi)}{r+\lambda_{d}+g(\varphi)} \gamma\left(\frac{\partial \pi^{I, B}\left(N_{i}^{B}, 0, k_{i}\right)}{\partial N_{i}^{B}}+f\right) \\
w^{I, B}\left(y, N_{i}^{B}\right) & =(1-\gamma) r U+\gamma \alpha y\left(N_{i}^{B}\right)^{\alpha-1}-\gamma \frac{\partial w^{I, B}\left(y, N_{i}^{B}\right)}{\partial N_{i}^{B}} N_{i}^{B}+\gamma r f \\
& +\delta \frac{g(\varphi) \beta}{r+\lambda_{d}+g(\varphi)} \gamma\left(\frac{\partial \pi^{I, B}\left(N_{i}^{B}, 0, k_{i}\right)}{\partial N_{i}^{B}}+f\right) \\
w^{I, B}\left(0, N_{i}^{B}\right) & =(1-\gamma) r U-\gamma \frac{\partial w^{I, B}\left(0, N_{i}^{B}\right)}{\partial N_{i}^{B}} N_{i}^{B}+\gamma\left(r+\lambda_{d}\right) f \\
& -\beta g(\varphi) \gamma\left(\frac{\partial \pi^{I, B}\left(N_{i}^{B}, y, k_{i}\right)}{\partial N_{i}^{B}}+f\right)
\end{aligned}
$$

where the last term in each line, i.e., a fraction of firms' surplus, appears due to innovation price bargaining. Since wages of outsiders and insiders at a firm with $y_{i}=y$ only differ in a constant, we know that the $\partial w^{O, B}\left(y, N_{i}^{B}\right) / \partial N_{i}^{B}=\partial w^{I, B}\left(y, N_{i}^{B}\right) / \partial N_{i}^{B}$. This allows us to write the differences in wages between ousiders and insiders as,

$$
w^{I, B}\left(y, N_{i}^{B}\right)-w^{O, B}\left(y, N_{i}^{B}\right)=\gamma(r+\delta) f .
$$

Substituting allows us to write the difference in the marginal values of employing an outsider and an insider as,

$$
\frac{\partial \pi^{O, B}\left(N_{i}^{B}, y, k_{i}\right)}{\partial N_{i}^{B}}-\frac{\partial \pi^{I, B}\left(N_{i}^{B}, y, k_{i}\right)}{\partial N_{i}^{B}}=\frac{w^{I, B}\left(y, N_{i}^{B}\right)-w^{O, B}\left(y, N_{i}^{B}\right)}{(r+\delta)}=\gamma f .
$$

Given the vacancy creation condition, we can write the marginal value of employing an insider as

$$
\frac{\partial \pi^{I, B}\left(N_{i}^{B}, y, k_{i}\right)}{\partial N_{i}^{B}}=\frac{\partial \pi^{O, B}\left(N_{i}^{B}, y, k_{i}\right)}{\partial N_{i}^{B}}-\gamma f=\frac{c}{\lambda_{m}(\theta)}-\gamma f
$$


This allows us to determine the wage for an insider at a firm with $y_{i}=0$,

$$
w^{I, B}\left(0, N_{i}^{B}\right)=(1-\gamma) r U+\gamma\left(r+\lambda_{d}\right) f-\beta g(\varphi) \gamma\left(\frac{c}{\lambda_{m}(\theta)}+(1-\gamma) f\right)
$$

where we used the fact that the differential equation is independent of $N_{i}^{B}$.

Substituting implies that the marginal value of employing an insider with $y_{i}=0$ is independent of the number of employed workers, i.e.,

$$
\frac{\partial \pi^{I, B}\left(N_{i}^{B}, 0, k_{i}\right)}{\partial N_{i}^{B}}=\frac{g(\varphi)(1-\beta)\left(\frac{c}{\lambda_{m}(\theta)}-\gamma f\right)-w^{I, B}\left(0, N_{i}^{B}\right)}{\left(r+\lambda_{d}+g(\varphi)(1-\beta)\right)} .
$$

This allows us to write the wage equation for an outsider and an insider at a firm with $y_{i}=y$ as,

$$
\begin{aligned}
w^{O, B}\left(y, N_{i}^{B}\right) & =(1-\gamma) r U+\gamma \frac{\alpha}{1-\gamma(1-\alpha)} y\left(N_{i}^{B}\right)^{\alpha-1}-\delta \gamma f \\
& +\delta \beta g(\varphi) \gamma \frac{g(\varphi)(1-\beta)\left(\frac{c}{\lambda_{m}(\theta)}-\gamma f\right)-w^{I, B}\left(0, N_{i}^{B}\right)}{\left(r+\lambda_{d}+g(\varphi)\right)\left(r+\lambda_{d}+g(\varphi)(1-\beta)\right)}, \\
w^{I, B}\left(y, N_{i}^{B}\right)= & (1-\gamma) r U+\gamma \frac{\alpha}{1-\gamma(1-\alpha)} y\left(N_{i}^{B}\right)^{\alpha-1}+\gamma r f \\
& +\delta \beta g(\varphi) \gamma \frac{g(\varphi)(1-\beta)\left(\frac{c}{\lambda_{m}(\theta)}-\gamma f\right)-w^{I, B}\left(0, N_{i}^{B}\right)}{\left(r+\lambda_{d}+g(\varphi)\right)\left(r+\lambda_{d}+g(\varphi)(1-\beta)\right)},
\end{aligned}
$$

Substituting the value of being unemployed by $(1-\gamma) r U=(1-\gamma) z+\gamma \theta c$ gives the wage equation in section 2.4.3.

\section{A.2 Firing conditions}

The firing conditions for type $R$ and type $B$ firms are given by,

$$
\frac{\partial \pi^{I, R}\left(N_{i}^{R}, 0, k_{i}\right)}{\partial N_{i}^{R}}+f<0 \text {, and } \frac{\partial \pi^{I, B}\left(N_{i}^{B}, 0, k_{i}\right)}{\partial N_{i}^{B}}+f<0 .
$$

Using the respective marginal values of a worker from section A.1 and the fact that,

$$
\frac{\partial \pi^{O, t}\left(N_{i}^{t}, y, k_{i}\right)}{\partial N_{i}^{t}}-\frac{\partial \pi^{I, t}\left(N_{i}^{t}, y, k_{i}\right)}{\partial N_{i}^{t}}=\frac{w^{I, t}\left(y, N_{i}^{t}\right)-w^{O, t}\left(y, N_{i}^{t}\right)}{(r+\delta)}=\gamma f,
$$

and that the vacancy creation condition,

$$
\frac{\partial \pi^{O, t}\left(N_{i}^{t}, y, k_{i}\right)}{\partial N_{i}^{t}}=\frac{c}{\lambda_{m}(\theta)}
$$

gives the firing conditions in section 2.6. 


\section{A.3 Vacancy creation conditions}

Using the respective marginal values of a worker from section A.1 and the fact that,

$$
\frac{\partial \pi^{O, t}\left(N_{i}^{t}, y, k_{i}\right)}{\partial N_{i}^{t}}-\frac{\partial \pi^{I, t}\left(N_{i}^{t}, y, k_{i}\right)}{\partial N_{i}^{t}}=\frac{w^{I, t}\left(y, N_{i}^{t}\right)-w^{O, t}\left(y, N_{i}^{t}\right)}{(r+\delta)}=\gamma f
$$

where

$$
\begin{aligned}
\frac{\partial \pi^{I, R}\left(N_{i}^{R}, y, k_{i}\right)}{\partial N_{i}^{R}} & =\frac{\frac{(1-\gamma) \alpha}{1-\gamma(1-\alpha)} y\left(N_{i}^{R}\right)^{\alpha-1}-(1-\gamma) r U-\gamma r f+\delta \frac{\partial \pi^{I, R}\left(N_{i}^{R}, 0, k_{i}\right)}{\partial N_{i}^{R}}}{(r+\delta)} \\
& =\frac{\frac{(1-\gamma) \alpha}{1-\gamma(1-\alpha)} y\left(N_{i}^{R}\right)^{\alpha-1}-(1-\gamma) r U-\gamma r f}{(r+\delta)} \\
& +\frac{\delta}{(r+\delta)} \frac{\eta\left(\frac{c}{\lambda_{m}(\theta)}+(1-\gamma) f\right)-w^{I, R}\left(0, N_{i}^{R}\right)-\eta f}{\left(r+\lambda_{d}+\eta\right)} \\
& =\frac{\frac{(1-\gamma) \alpha}{1-\gamma(1-\alpha)} y\left(N_{i}^{R}\right)^{\alpha-1}-(1-\gamma) r U-\gamma r f}{(r+\delta)} \\
& +\frac{\delta}{(r+\delta)} \frac{\eta \frac{c}{\lambda_{m}(\theta)}-(1-\gamma) r U-\gamma\left(r+\lambda_{d}+\eta\right) f}{\left(r+\lambda_{d}+\eta\right)}
\end{aligned}
$$

and using the fact that

$$
\frac{\partial \pi^{O, t}\left(N_{i}^{t}, y, k_{i}\right)}{\partial N_{i}^{t}}=\frac{\partial \pi^{I, t}\left(N_{i}^{t}, y, k_{i}\right)}{\partial N_{i}^{t}}+\gamma f=\frac{c}{\lambda_{m}(\theta)}
$$

implies

$$
\begin{aligned}
\frac{c}{\lambda_{m}(\theta)} & =\frac{\frac{(1-\gamma) \alpha}{1-\gamma(1-\alpha)} y\left(N_{i}^{R}\right)^{\alpha-1}-(1-\gamma) r U}{(r+\delta)} \\
& +\frac{\delta}{(r+\delta)} \frac{\eta \frac{c}{\lambda_{m}(\theta)}-(1-\gamma) r U}{\left(r+\lambda_{d}+\eta\right)} \\
\frac{c}{\lambda_{m}(\theta)} & =\frac{\left(r+\lambda_{d}+\eta\right) \frac{(1-\gamma) \alpha}{1-\gamma(1-\alpha)} y\left(N_{i}^{R}\right)^{\alpha-1}-\left(r+\delta+\lambda_{d}+\eta\right)(1-\gamma) r U}{(r+\delta)\left(r+\lambda_{d}\right)+r \eta}
\end{aligned}
$$


Similarly for type $B$ firms, i.e.,

$$
\begin{aligned}
\frac{\partial \pi^{I, B}\left(N_{i}^{B}, y, k_{i}\right)}{\partial N_{i}^{B}} & =\frac{\alpha y\left(N_{i}^{B}\right)^{\alpha-1}-w^{I, B}\left(y, N_{i}^{B}\right)-\frac{\partial w^{I, B}\left(y, N_{i}^{B}\right)}{\partial N_{i}^{B}} N_{i}^{B}+\delta \frac{\partial \pi^{I, B}\left(N_{i}^{B}, 0, k_{i}\right)}{\partial N_{i}^{B}}}{(r+\delta)} \\
& =\frac{\frac{(1-\gamma) \alpha}{1-\gamma(1-\alpha)} y\left(N_{i}^{B}\right)^{\alpha-1}-(1-\gamma) r U-\gamma(r+\delta) f-\delta(1-\gamma) f}{(r+\delta)} \\
& +\frac{\delta}{(r+\delta)} \frac{r+\lambda_{d}+g(\varphi)-g(\varphi) \gamma \beta}{r+\lambda_{d}+g(\varphi)}\left(\frac{\partial \pi^{I, B}\left(N_{i}^{B}, 0, k_{i}\right)}{\partial N_{i}^{B}}+f\right) .
\end{aligned}
$$

Using the fact that

$$
\frac{\partial \pi^{O, t}\left(N_{i}^{t}, y, k_{i}\right)}{\partial N_{i}^{t}}=\frac{\partial \pi^{I, t}\left(N_{i}^{t}, y, k_{i}\right)}{\partial N_{i}^{t}}+\gamma f=\frac{c}{\lambda_{m}(\theta)},
$$

implies

$$
\begin{aligned}
& \frac{c}{\lambda_{m}(\theta)}=\frac{\frac{(1-\gamma) \alpha}{1-\gamma(1-\alpha)} y\left(N_{i}^{B}\right)^{\alpha-1}-(1-\gamma) r U-\delta(1-\gamma) f}{(r+\delta)} \\
& +\frac{\delta}{(r+\delta)} \frac{r+\lambda_{d}+g(\varphi)-g(\varphi) \gamma \beta}{r+\lambda_{d}+g(\varphi)}\left(\frac{\partial \pi^{I, B}\left(N_{i}^{B}, 0, k_{i}\right)}{\partial N_{i}^{B}}+f\right) \\
& \frac{c}{\lambda_{m}(\theta)}=\frac{\frac{(1-\gamma) \alpha}{1-\gamma(1-\alpha)} y\left(N_{i}^{B}\right)^{\alpha-1}-(1-\gamma) r U-\delta(1-\gamma) f}{(r+\delta)} \\
& +\frac{\delta}{(r+\delta)} \frac{r+\lambda_{d}+g(\varphi)-g(\varphi) \gamma \beta}{\left(r+\lambda_{d}+g(\varphi)\right)} \frac{g(\varphi)(1-(1-\gamma) \beta) \frac{c}{\lambda_{m}(\theta)}-(1-\gamma) r U}{\left(r+\lambda_{d}+g(\varphi)(1-\beta)\right)} \\
& +\frac{\delta}{(r+\delta)} \frac{r+\lambda_{d}+g(\varphi)-g(\varphi) \gamma \beta}{r+\lambda_{d}+g(\varphi)} \frac{r+\lambda_{d}+g(\varphi)(1-\beta)+g(\varphi) \gamma \beta}{r+\lambda_{d}+g(\varphi)(1-\beta)}(1-\gamma) f, \\
& =\frac{\frac{(1-\gamma) \alpha}{1-\gamma(1-\alpha)} y\left(N_{i}^{B}\right)^{\alpha-1}}{(r+\delta)} \\
& -\left(1+\delta \frac{\left(r+\lambda_{d}+g(\varphi)-g(\varphi) \gamma \beta\right)}{\left(r+\lambda_{d}+g(\varphi)\right)\left(r+\lambda_{d}+g(\varphi)(1-\beta)\right)}\right) \frac{(1-\gamma) r U}{(r+\delta)} \\
& +\frac{\delta}{(r+\delta)} \frac{\left(r+\lambda_{d}+g(\varphi)-g(\varphi) \gamma \beta\right) g(\varphi)(1-(1-\gamma) \beta)}{\left(r+\lambda_{d}+g(\varphi)\right)\left(r+\lambda_{d}+g(\varphi)(1-\beta)\right)} \frac{c}{\lambda_{m}(\theta)} \\
& +\frac{g(\varphi) \beta(1-\gamma) g(\varphi) \gamma \beta}{\left(r+\lambda_{d}+g(\varphi)\right)\left(r+\lambda_{d}+g(\varphi)(1-\beta)\right)} \frac{\delta}{(r+\delta)}(1-\gamma) f
\end{aligned}
$$


Rearranging implies,

$$
\begin{aligned}
\frac{c}{\lambda_{m}(\theta)} & =\frac{C_{2}}{C_{1}}\left(\frac{(1-\gamma) \alpha}{1-\gamma(1-\alpha)} y\left(N_{i}^{B}\right)^{\alpha-1}-(1-\gamma) r U\right) \\
& -\frac{r+\lambda_{d}+g(\varphi)-g(\varphi) \gamma \beta}{C_{1}} \delta(1-\gamma) r U \\
& +\frac{g(\varphi) \beta(1-\gamma) g(\varphi) \gamma \beta}{C_{1}} \delta(1-\gamma) f
\end{aligned}
$$

with

$$
\begin{aligned}
& C_{1}=C_{2}(r+\delta)-\left(r+\lambda_{d}+g(\varphi)-\gamma \beta g(\varphi)\right) \delta(1-(1-\gamma) \beta) g(\varphi) \\
& C_{2}=\left(r+\lambda_{d}+g(\varphi)\right)\left(r+\lambda_{d}+g(\varphi)(1-\beta)\right)
\end{aligned}
$$

\section{A.4 Innovation price}

The innovation price is given by the surplus splitting rule,

$$
\begin{aligned}
p\left(k_{j}, 0\right) & =\beta\left(\pi^{O, B}\left(N_{i}^{B}, y, k_{i}\right)-\frac{c}{\lambda_{m}(\theta)} N_{i}^{B}-\pi^{O, B}\left(0,0, k_{i}\right)\right) \\
& +(1-\beta)\left(\pi^{S}\left(0, y, k_{j}\right)-\pi^{S}\left(0,0, k_{j}\right)\right), \\
p\left(k_{j}, N_{i}^{B}\right) & =\beta\left(\pi^{I, B}\left(N_{i}^{B}, y, k_{i}\right)-\pi^{I, B}\left(N_{i}^{B}, 0, k_{i}\right)\right) \\
& +(1-\beta)\left(\pi^{S}\left(0, y, k_{j}\right)-\pi^{S}\left(0,0, k_{j}\right)\right) .
\end{aligned}
$$

The closed form expressions for the expected profit of type $S$ firms that sell their innovations and of type $B$ firms that buy innovations are as follows. Given the fact that the price that a type $S$ firm with innovation cost $k_{i}$ is given by $p\left(k_{i}, 0\right)$ or $p\left(k_{i}, N_{j}^{B}\right)$, respectively, and using equations (8) and (7) the expected profit with $y_{i} \in\{0, y\}$ can be written as,

$$
\begin{aligned}
\pi^{S}\left(0, y, k_{i}\right) & =\frac{\left(r+\lambda_{s}+\eta\right) \varphi g(\varphi) p\left(k_{i}, N\right)-(\delta+\varphi g(\varphi)) k_{i}}{r\left(r+\lambda_{s}+\eta\right)+(\delta+\varphi g(\varphi))\left(r+\lambda_{s}\right)} \\
\pi^{S}\left(0,0, k_{i}\right) & =\frac{\eta \varphi g(\varphi) p\left(k_{i}, N\right)-(r+\delta+\varphi g(\varphi)) k_{i}}{r\left(r+\lambda_{s}+\eta\right)+(\delta+\varphi g(\varphi))\left(r+\lambda_{s}\right)}
\end{aligned}
$$

where $N=N_{j}^{B}$ if $L_{j}^{B}=0$ and $N=0$ if $L_{j}^{B}=N_{j}^{B}$. Using equations (9) and (13) the expected profit for firms that do not lay off their workers if they are hit by a productivity 
shock can be written as,

$$
\begin{aligned}
\pi^{I, B}\left(N_{i}^{B}, y, k_{i}\right) & =\frac{\left(r+\lambda_{d}+g(\varphi)\right)\left(y\left(N_{i}^{B}\right)^{\alpha}-w^{I, B}\left(y, N_{i}^{B}\right) N_{i}^{B}\right)}{\left(r+\lambda_{d}\right)(r+\delta)+g(\varphi) r} \\
& -\delta \frac{w^{I, B}\left(0, N_{i}^{B}\right) N_{i}^{B}+g(\varphi) E_{k_{j}}\left[p\left(k_{j}, N_{i}^{B}\right)\right]}{\left(r+\lambda_{d}\right)(r+\delta)+g(\varphi) r}, \\
\pi^{I, B}\left(N_{i}^{B}, 0, k_{i}\right) & =\frac{g(\varphi)\left(y\left(N_{i}^{B}\right)^{\alpha}-w^{I, B}\left(y, N_{i}^{B}\right) N_{i}^{B}\right)}{\left(r+\lambda_{d}\right)(r+\delta)+g(\varphi) r} \\
& -(r+\delta) \frac{w^{I, B}\left(0, N_{i}^{B}\right) N_{i}^{B}+g(\varphi) E_{k_{j}}\left[p\left(k_{j}, N_{i}^{B}\right)\right]}{\left(r+\lambda_{d}\right)(r+\delta)+g(\varphi) r} .
\end{aligned}
$$

If workers are laid off in case of a productivity shock, the expected profits are given by,

$$
\begin{aligned}
\pi^{O, B}\left(N_{i}^{B}, y, k_{i}\right) & =\frac{\left(r+\lambda_{d}+g(\varphi)\right)\left(y\left(N_{i}^{B}\right)^{\alpha}-w^{O, B}\left(y, N_{i}^{B}\right) N_{i}^{B}-\delta f N_{i}^{B}\right)}{\left(r+\lambda_{d}\right)(r+\delta)+g(\varphi) r} \\
& -\frac{\delta g(\varphi)}{\left(r+\lambda_{d}\right)(r+\delta)+g(\varphi) r}\left(\frac{c}{\lambda_{m}(\theta)} N_{i}^{B}+E_{k_{j}}\left[p\left(k_{j}, 0\right)\right]\right), \\
\pi^{O, B}\left(0,0, k_{i}\right) & =\frac{g(\varphi)\left(y\left(N_{i}^{B}\right)^{\alpha}-w^{O, B}\left(y, N_{i}^{B}\right) N_{i}^{B}-\delta f N_{i}^{B}\right)}{\left(r+\lambda_{d}\right)(r+\delta)+g(\varphi) r} \\
& -\frac{(r+\delta) g(\varphi)}{\left(r+\lambda_{d}\right)(r+\delta)+g(\varphi) r}\left(\frac{c}{\lambda_{m}(\theta)} N_{i}^{B}+E_{k_{j}}\left[p\left(k_{j}, 0\right)\right]\right) .
\end{aligned}
$$

Computing the differences in expected profits using equations (46) to (51) and plugging the results into the innovation price equations (44) and (45) leads to equations (27) and (28) for the expected innovation price.

Given the expected price in equation $(27)$ or $(28)$ the innovation price $p\left(k_{j}, N_{i}^{B}\right)$ or $p\left(k_{j}, 0\right)$ for a seller with innovation cost $k_{j}$ is given by substituting the expected price in the respective expected profit functions (46) to (51) and inserting them into the innovation price equations (44) and (45). Rearranging implies,

$$
\begin{aligned}
p\left(k_{j}, N_{i}^{B}\right) & =\frac{K_{2} \beta\left(r+\lambda_{d}\right)\left(y\left(N_{i}^{B}\right)^{\alpha}-w^{I, B}\left(y, N_{i}^{B}\right) N_{i}^{B}\right)+K_{2} \beta r w^{B}\left(0, N_{i}^{B}\right) N_{i}^{B}}{K_{1} K_{2}-K_{1}(1-\beta)\left(r+\lambda_{s}\right) \varphi g(\varphi)} \\
& +\frac{K_{1}(1-\beta) r k_{j}+K_{2} \beta r g(\varphi) p\left(\bar{k}, N_{i}^{B}\right)}{K_{1} K_{2}-K_{1}(1-\beta)\left(r+\lambda_{s}\right) \varphi g(\varphi)}, \\
p\left(k_{j}, 0\right) & =\frac{K_{2} \beta\left(r+\lambda_{d}\right)\left(y\left(N_{i}^{B}\right)^{\alpha}-w^{O, B}\left(y, N_{i}^{B}\right) N_{i}^{B}-\delta f N_{i}^{B}-(r+\delta) \frac{c}{\lambda_{m}(\theta)} N_{i}^{B}\right)}{K_{1} K_{2}-K_{1}(1-\beta)\left(r+\lambda_{s}\right) \varphi g(\varphi)} \\
& +\frac{K_{1}(1-\beta) r k_{j}+K_{2} \beta r g(\varphi) p(\bar{k}, 0)}{K_{1} K_{2}-K_{1}(1-\beta)\left(r+\lambda_{s}\right) \varphi g(\varphi)} .
\end{aligned}
$$




\section{A.5 Type choice}

The closed form expression for the expected profit of type $R$ firms is obtained by rearranging equations (9) to (11), i.e.,

$$
\pi^{O, R}\left(N_{i}^{R}, y, k_{i}\right)=\left\{\begin{array}{c}
\frac{\left(r+\lambda_{d}+\eta\right)\left(y\left(N_{i}^{R}\right)^{\alpha}-w^{O, R}\left(y, N_{i}^{R}\right) N_{i}^{R}\right)-\delta k_{i}}{\left(\left(r+\lambda_{d}\right)(r+\delta)+r \eta\right)} \\
-\delta \frac{w^{I, R}\left(0, N_{i}^{R}\right) N_{i}^{R}+\eta \gamma f N_{i}^{R}}{\left(\left(r+\lambda_{d}\right)(r+\delta)+r \eta\right)} \text { if } L_{i}^{R}=0, \\
\frac{\left(r+\lambda_{d}+\eta\right)\left(y\left(N_{i}^{R}\right)^{\alpha}-w^{O, R}\left(y, N_{i}^{R}\right) N_{i}^{R}-\delta f N_{i}^{R}\right)-\delta k_{i}}{\left(r+\lambda_{d}\right)(r+\delta)+r \eta} \\
-\frac{\delta \eta}{\left(r+\lambda_{d}\right)(r+\delta)+r \eta} \frac{c}{\lambda_{m}(\theta)} N_{i}^{R} \text { if } L_{i}^{R}=N_{i}^{R},
\end{array}\right.
$$

The expected profit is strictly decreasing in $k_{i}$, which makes it less attractive for high innovation cost firms to do own research if they are hit by a productivity shock.

Type $S$ firms that only innovate in order to sell their innovations obtain the expected profit $\pi^{S}\left(0, y, k_{i}\right)$, where substituting the price $p\left(k_{i}, N\right)$ implies,

$$
\begin{aligned}
\pi^{S}\left(0, y, k_{i}\right)= & \frac{\left(r+\lambda_{s}+\eta\right) \varphi g(\varphi) \beta\left(r+\lambda_{d}\right)\left(y\left(N_{j}^{B}\right)^{\alpha}-w^{B}\left(y, N_{j}^{B}\right) N_{j}^{B}\right)}{\left(\left(r+\lambda_{d}\right)(r+\delta)+g(\varphi) r\right)\left(\left(r+\lambda_{s}\right)(r+\delta+\beta \varphi g(\varphi))+r \eta\right)} \\
+ & \frac{\left(r+\lambda_{s}+\eta\right) \varphi g(\varphi) \beta\left(r w^{B}\left(0, N_{j}^{B}\right) N_{j}^{B}+r g(\varphi) p\left(\bar{k}_{i}, N_{j}^{B}\right)\right)}{\left(\left(r+\lambda_{d}\right)(r+\delta)+g(\varphi) r\right)\left(\left(r+\lambda_{s}\right)(r+\delta+\beta \varphi g(\varphi))+r \eta\right)} \\
& -\frac{(\delta+\beta \varphi g(\varphi))}{\left(r+\lambda_{s}\right)(r+\delta+\beta \varphi g(\varphi))+r \eta} k_{i} \text { if } L_{j}^{B}=0, \\
\pi^{S}\left(0, y, k_{i}\right)= & \frac{\left(r+\lambda_{s}+\eta\right) \varphi g(\varphi) \beta\left(r+\lambda_{d}\right)\left(y\left(N_{j}^{B}\right)^{\alpha}-w^{B}\left(y, N_{j}^{B}\right) N_{j}^{B}-\delta f N_{j}^{B}\right)}{\left((r+\delta)\left(r+\lambda_{d}\right)+r g(\varphi)\right)\left((r+\delta)\left(r+\lambda_{s}\right)+\beta \varphi g(\varphi)\left(r+\lambda_{d}\right)+r \eta\right)} \\
+ & \frac{\left(r+\lambda_{s}+\eta\right) \varphi g(\varphi) \beta\left(-\left(r+\lambda_{d}\right)\left((r+\delta) \frac{c}{\lambda_{m}(\theta)} N_{j}^{B}\right)+r g(\varphi) p\left(\bar{k}_{j}, 0\right)\right)}{\left((r+\delta)\left(r+\lambda_{d}\right)+r g(\varphi)\right)\left((r+\delta)\left(r+\lambda_{s}\right)+\beta \varphi g(\varphi)\left(r+\lambda_{d}\right)+r \eta\right)} \\
& -\frac{(\delta+\beta \varphi g(\varphi))}{\left(r+\lambda_{s}\right)(r+\delta+\beta \varphi g(\varphi))+r \eta} k_{i} \text { if } L_{j}^{B}=N_{j}^{B},
\end{aligned}
$$

The expected profit $\pi^{S}\left(0, y, k_{i}\right)$ is strictly decreasing in $k_{i}$. Comparing how the expected profit of type $S$ and $R$ firms change with the innovation cost $k_{i}$ reveals,

$$
\frac{\partial \pi^{O, R}\left(N_{i}^{R}, y, k_{i}\right)}{\partial k_{i}}=\frac{\delta}{\left(r+\lambda_{d}\right)(r+\delta)+r \eta} \text { for any } L_{i}^{R} .
$$




$$
\begin{aligned}
& \frac{\partial \pi^{S}\left(0, y, k_{i}\right)}{\partial k_{i}}-\frac{\partial \pi^{O, R}\left(N_{i}^{R}, y, k_{i}\right)}{\partial k_{i}} \\
& =\frac{\delta}{(r+\delta)\left(r+\lambda_{d}+\eta\right)}\left(1+\frac{\eta \delta}{\left(\left(r+\lambda_{d}\right)(r+\delta)+r \eta\right)}\right)-\frac{(\delta+\beta \varphi g(\varphi))}{\left(r+\lambda_{s}\right)(r+\delta+\beta \varphi g(\varphi))+r \eta} \\
& =\frac{\delta}{\left(r+\lambda_{d}\right)(r+\delta)+r \eta}-\frac{(\delta+\beta \varphi g(\varphi))}{\left(r+\lambda_{s}\right)(r+\delta+\beta \varphi g(\varphi))+r \eta} \\
& =\frac{\left(\lambda_{s}-\lambda_{d}\right)(r \delta+\delta)-\left(r+\lambda_{d}+\eta\right) r \beta \varphi g(\varphi)}{\left(\left(r+\lambda_{d}\right)(r+\delta)+r \eta\right)\left(\left(r+\lambda_{s}\right)(r+\delta+\beta \varphi g(\varphi))+r \eta\right)}<0 .
\end{aligned}
$$

since $\lambda_{s}<\lambda_{d}$ by assumption.

\section{A.6 Worker flows and labor market tightness}

We denote the measure of employed workers by $l$ and the measure of unemployed workers by $u$. Let us first consider the case when all firms keep their workers if they are hit by a productivity shock. We can determine the steady state measure of employed workers by equating the in- and outflow from unemployment, i.e.,

$$
\begin{aligned}
\theta \lambda_{m}(\theta) u & =\lambda_{d}\left(m^{B}\left(0, N_{i}^{B}\right) N_{i}^{B}+m^{R}\left(0, N_{i}^{R}\right) N_{i}^{R}\right) \\
& =\lambda_{d}\left(N_{i}^{B}+\frac{\Gamma\left(k^{* *}\right)-\Gamma\left(k^{*}\right)}{1-\Gamma\left(k^{* *}\right)} N_{i}^{R}\right) m^{B}\left(0, N_{i}^{B}\right) .
\end{aligned}
$$

The level of employment $l$ can be obtained by summing over all type $B$ and $R$ firms, i.e.,

$$
\begin{aligned}
l & =\left(m^{B}\left(0, N_{i}^{B}\right)+m^{B}\left(y, N_{i}^{B}\right)\right) N_{i}^{B}+\left(m^{R}\left(0, N_{i}^{R}\right)+m^{R}\left(y, N_{i}^{R}\right)\right) N_{i}^{R}, \\
& =\left(\frac{\delta+\lambda_{d}+g(\varphi)}{\delta} N_{i}^{B}+\frac{\delta+\lambda_{d}+\eta}{\delta} \frac{\Gamma\left(k^{* *}\right)-\Gamma\left(k^{*}\right)}{1-\Gamma\left(k^{* *}\right)} N_{i}^{R}\right) m^{B}\left(0, N_{i}^{B}\right),
\end{aligned}
$$

where the flow equations for firms in equations (32) to (37) imply,

$$
\begin{aligned}
\frac{1}{m^{B}\left(0, N_{i}^{B}\right)} & =\left(\frac{1}{\varphi}+\frac{\delta+\varphi g(\varphi)}{\left(\lambda_{s}+\eta\right) \varphi}+\frac{\delta+\lambda_{d}+g(\varphi)}{\delta}\right) \frac{1}{m} \\
& +\frac{\delta+\lambda_{d}+\eta \Gamma\left(k^{* *}\right)-\Gamma\left(k^{*}\right)}{\delta} \frac{1}{1-\Gamma\left(k^{* *}\right)}
\end{aligned}
$$

Using the fact that the number of unemployed and employed workers have to add up to one, i.e., $l=1-u$, allows us to write the labor market tightness $\theta$ as a function of the number of workers employed at type $B$ and $R$ firms $N_{i}^{B}$ and $N_{i}^{R}$, as well as of 
$\left\{\varphi, k^{*}, k^{* *}, m\right\}$, i.e.,

$$
\begin{aligned}
& \left(\frac{\lambda_{d}}{\delta} \frac{\delta+\theta \lambda_{m}(\theta)}{\theta \lambda_{m}(\theta)}+\frac{\delta+g(\varphi)}{\delta}\right) N_{i}^{B}+\left(\frac{\lambda_{d}}{\delta} \frac{\delta+\theta \lambda_{m}(\theta)}{\theta \lambda_{m}(\theta)}+\frac{\delta+\eta}{\delta}\right) \frac{\Gamma\left(k^{* *}\right)-\Gamma\left(k^{*}\right)}{1-\Gamma\left(k^{* *}\right)} N_{i}^{R} \\
& =\left(\frac{1}{\varphi}+\frac{\delta+\varphi g(\varphi)}{\left(\lambda_{s}+\eta\right) \varphi}+\frac{\delta+\lambda_{d}+g(\varphi)}{\delta}+\frac{\delta+\lambda_{d}+\eta}{\delta} \frac{\Gamma\left(k^{* *}\right)-\Gamma\left(k^{*}\right)}{1-\Gamma\left(k^{* *}\right)}\right) \frac{1}{m}
\end{aligned}
$$

The vacancy creation conditions at type $B$ and $R$ firms can then be used to substitute out $N_{i}^{B}$ and $N_{i}^{R}$ to get an equation that solely determines $\theta$ as a function of $\left\{\varphi, k^{*}, k^{* *}, m\right\}$.

Let us now consider the case when all firms lay off workers if they are hit by a productivity shock. Equating in- and outflow into employment defines steady state employment as,

$$
\begin{aligned}
\frac{\theta \lambda_{m}(\theta)}{\delta+\theta \lambda_{m}(\theta)} & =l=\left(m^{B}\left(y, N_{i}^{B}\right)+m^{R}\left(y, N_{i}^{R}\right)\right) N_{i}^{t}, \\
& =\left(\frac{\lambda_{d}+g(\varphi)}{\delta}+\frac{\Gamma\left(k^{* *}\right)-\Gamma\left(k^{*}\right)}{1-\Gamma\left(k^{* *}\right)} \frac{\lambda_{d}+\eta}{\delta}\right) m^{B}\left(0, N_{i}^{B}\right) N_{i}^{t},
\end{aligned}
$$

where $1 / m^{B}\left(0, N_{i}^{B}\right)$ is given by equation (52). Substituting $m^{B}\left(0, N_{i}^{B}\right)$ again implies,

$$
\begin{aligned}
& \left(\frac{1}{\varphi}+\frac{\delta+\varphi g(\varphi)}{\left(\lambda_{s}+\eta\right) \varphi}+\frac{\delta+\lambda_{d}+g(\varphi)}{\delta}+\frac{\delta+\lambda_{d}+\eta}{\delta} \frac{\Gamma\left(k^{* *}\right)-\Gamma\left(k^{*}\right)}{1-\Gamma\left(k^{* *}\right)}\right) \frac{1}{m} \\
& =\left(\frac{\lambda_{d}+g(\varphi)}{\delta}+\frac{\Gamma\left(k^{* *}\right)-\Gamma\left(k^{*}\right)}{1-\Gamma\left(k^{* *}\right)} \frac{\lambda_{d}+\eta}{\delta}\right) \frac{\delta+\theta \lambda_{m}(\theta)}{\theta \lambda_{m}(\theta)} N_{i}^{t} .
\end{aligned}
$$

This again allows us to write the labor market tightness $\theta$ as a function of the number of workers $N_{i}^{t}$ employed at type $B$ and $R$ firms with $y_{i}=y$, as well as $\left\{\varphi, k^{*}, k^{* *}, m\right\}$. Again we can use the vacancy creation conditions for productive firms under $L_{i}^{t}=N_{i}^{t}$ to substitute out $N_{i}^{t}$.

If only type $B$ or only type $R$ firms lay off workers, if they are hit by a productivity shock, steady state unemployment and the respective employment level are given by,

$$
\begin{aligned}
\theta \lambda_{m}(\theta) u=\left\{\begin{array}{l}
\lambda_{d} m^{B}\left(0, N_{i}^{B}\right) N_{i}^{B}+\delta m^{R}\left(y, N_{i}^{R}\right) N_{i}^{R} \text { if } L_{i}^{B}=0 \text { and } L_{i}^{R}=N_{i}^{R}, \\
\lambda_{d} m^{R}\left(0, N_{i}^{R}\right) N_{i}^{R}+\delta m^{B}\left(y, N_{i}^{B}\right) N_{i}^{B} \text { if } L_{i}^{B}=N_{i}^{B} \text { and } L_{i}^{R}=0,
\end{array}\right. \\
l=\left\{\begin{array}{l}
\left(m^{B}\left(0, N_{i}^{B}\right)+m^{B}\left(y, N_{i}^{B}\right)\right) N_{i}^{B}+m^{R}\left(y, N_{i}^{R}\right) N_{i}^{R} \text { if } L_{i}^{B}=0 \text { and } L_{i}^{R}=N_{i}^{R}, \\
m^{B}\left(y, N_{i}^{B}\right) N_{i}^{B}+\left(m^{R}\left(0, N_{i}^{R}\right)+m^{R}\left(y, N_{i}^{R}\right)\right) N_{i}^{R} \text { if } L_{i}^{B}=N_{i}^{B} \text { and } L_{i}^{R}=0 .
\end{array}\right.
\end{aligned}
$$

The flow equations (32) to (37) then determine the respective measures for the number of firms of type $B$ and $R$. Using the fact that all workers have to add up to one, i.e., 
$l=1-u$, allows us again to write the labor market tightness $\theta$ as a function of the number of workers employed at type $B$ and $R$ firms $N_{i}^{B}$ and $N_{i}^{R}$, as well as of $\left\{\varphi, k^{*}, k^{* *}, m\right\}$, i.e., for $L_{i}^{B}=N_{i}^{B}$ and $L_{i}^{R}=0$,

$$
\begin{aligned}
& \left(\frac{1}{\varphi}+\frac{\delta+\varphi g(\varphi)}{\varphi\left(\lambda_{s}+\eta\right)}+\frac{\delta+\lambda_{d}+g(\varphi)}{\delta}+\frac{\delta+\lambda_{d}+\eta}{\delta} \frac{\Gamma\left(k^{* *}\right)-\Gamma\left(k^{*}\right)}{1-\Gamma\left(k^{* *}\right)}\right) \frac{1}{m} \\
& =\left(\frac{\lambda_{d}+g(\varphi)}{\theta \lambda_{m}(\theta)}+\frac{\lambda_{d}+g(\varphi)}{\delta}\right) N_{i}^{B}+\left(\frac{\lambda_{d}}{\theta \lambda_{m}(\theta)}+\frac{\delta+\lambda_{d}+\eta}{\delta}\right) \frac{\Gamma\left(k^{* *}\right)-\Gamma\left(k^{*}\right)}{1-\Gamma\left(k^{* *}\right)} N_{i}^{R},
\end{aligned}
$$

and for $L_{i}^{B}=0$ and $L_{i}^{R}=N_{i}^{R}$,

$$
\begin{aligned}
& \left(\frac{1}{\varphi}+\frac{\delta+\varphi g(\varphi)}{\varphi\left(\lambda_{s}+\eta\right)}+\frac{\delta+\lambda_{d}+g(\varphi)}{\delta}+\frac{\delta+\lambda_{d}+\eta}{\delta} \frac{\Gamma\left(k^{* *}\right)-\Gamma\left(k^{*}\right)}{1-\Gamma\left(k^{* *}\right)}\right) \frac{1}{m} \\
& =\left(\frac{\lambda_{d}}{\theta \lambda_{m}(\theta)}+\frac{\delta+\lambda_{d}+g(\varphi)}{\delta}\right) N_{i}^{B}+\left(\frac{\lambda_{d}+\eta}{\theta \lambda_{m}(\theta)}+\frac{\lambda_{d}+\eta}{\delta}\right) \frac{\Gamma\left(k^{* *}\right)-\Gamma\left(k^{*}\right)}{1-\Gamma\left(k^{* *}\right)} N_{i}^{R} .
\end{aligned}
$$

Keeping the variables $\left\{\varphi, k^{*}, k^{* *}, m\right\}$ constant, equations (53) to (56) determine the respective increasing functions of the number of workers employed at the respective firms, i.e., $\theta\left(N_{i}^{R}, N_{i}^{B}\right)$ with $\partial \theta\left(N_{i}^{R}, N_{i}^{B}\right) / \partial N_{i}^{t}>0$. 